\title{
Fixação do potássio nos solos portugueses
}

\section{Potassium fixation in Portuguese soils}

\author{
Ester Portela e Maria Manuela Abreu² \\ ${ }^{1}$ Centro de Investigação e Tecnologias Agro-Ambientais e Biológicas (CITAB), Universidade de Trás-os-Montes e Alto Douro, 5001-801, Vila Real, Portugal \\ 2 Linking Landscape, Environment, Agriculture and Food Research Centre (LEAF), Instituto Superior de Agronomia, Universidade de Lisboa, Tapada da Ajuda, 1349-017 Lisboa, Portugal \\ (*E-mail:eportela@utad.pt) \\ http://dx.doi.org/10.19084/RCA18100
}

Recebido/received: 2018.04.09

Recebido em versão revista/received in revised form: 2018.06.14

Aceite/accepted: 2018.06.14

\section{R E S U M O}

Em Portugal, desde os anos 30 do século XX, os resultados da experimentação relativa à adubação potássica têm amiúde causado perplexidade entre os investigadores. Nos casos em que se esperariam respostas evidentes ao K, devido às suas baixas concentrações no solo, elas ou não se verificaram, ou tardaram a surgir, sobretudo no Sul do país. Neste trabalho de revisão, faz-se uma retrospectiva da experimentação realizada, na qual parece evidente a ineficácia da adubação potássica. Inventariaram-se as unidades-solo onde foram detectados indícios da fixação do K através de ensaios experimentais, bem como as unidades-solo submetidas a ensaios laboratoriais em que foi evidente a sua elevada capacidade de fixação do K. Relativamente à fixação, além da identificação dos solos fixadores de K, discutiram-se ainda os factores propícios à fixação deste nutriente, dos quais se salienta a composição mineralógica dos solos nas fracções argila, limo e areia fina. Por fim, com base nos estudos já realizados apontam-se estratégias a seguir na adubação potássica.

Palavras-chave: filossilicatos, mineralogia das fracções do solo, potássio extraível, potássio de troca, capacidade de fixação do potássio

\begin{abstract}
A B S T R A C T
In Portugal, since the 1930s, the results of experimentation on potassium fertilization have frequently caused perplexity among researchers. In such cases, where clear responses to $\mathrm{K}$ were expected due to low $\mathrm{K}$ concentrations in the soils, they did not occur or were very slow in manifesting themselves, particularly in the south of the country. In this review paper a retrospective of the existing experimentation was carried out where the inefficacy of $\mathrm{K}$ fertilization was evident. In addition, an inventory of soil types was made where evidence of $\mathrm{K}$ fixation had been most often detected, either through experimental trials or through laboratory tests. The laboratory data refer to the determination of soil $\mathrm{K}$ fixation capacity. With regard to $\mathrm{K}$ fixation, in addition to the identification of the K-fixing soils, the propitious factors for fixation of this nutrient are discussed, highlighting the mineralogical composition of soils in the clay, silt and fine sand fractions. Finally, based on the studies already carried out, some strategies to be followed in potassium fertilization were proposed.
\end{abstract}

Keywords: phyllosilicates, mineralogy of soil fractions, extractable potassium, exchangeable potassium, potassium fixation capacity

\section{INTRODUÇÃO}

$\mathrm{O} \mathrm{K}$ é um macronutriente essencial a todos os organismos vivos e o mais importante catião sob o ponto de vista da sua concentração nos tecidos das plantas, mas é, também, crucial às suas funções fisiológicas e bioquímicas.
A libertação do $\mathrm{K}$ resultante da meteorização de vários minerais foi o suporte quase exclusivo da nutrição potássica das culturas durante centenas de anos. Porém, este processo não é ilimitado e, em muitos solos, haverá a tendência para se esgotarem as reservas de K. Ou seja, as taxas de libertação do K não são suficientemente elevadas para satisfazer as necessidades das plantas, portanto, para 
se assegurar a produtividade das culturas é necessário recorrer à fertilização potássica.

Em Portugal, desde o início do século XX, que a importação de adubos potássicos, bem como o seu consumo era muito baixa (Graça, 1939). Todavia, o seu consumo e a experimentação informal com adubos potássicos feita por agricultores do Baixo Alentejo, já decorria nos finais do século XIX assim como a execução de análises químicas aos solos, que, nessa data, eram efectuadas por Rebelo da Silva e destinavam-se à avaliação da disponibilidade do P e do K nos solos (Fernandes, 1899).

Em 1937, as taxas de aplicação de adubo potássico ainda eram bastante reduzidas, em particular se se tiver em conta os valores médios de consumo por hectare de área cultivada (Graça, 1939). Este autor indica que o consumo médio de $\mathrm{K}$ por área cultivada era cerca de $0,8 \mathrm{~kg} \mathrm{~K}_{2} \mathrm{O} \mathrm{ha}^{-1}$, o qual em comparação com o de outros países europeus (0,9-46 kg $\mathrm{K}_{2} \mathrm{O}$ ha $^{-1}$ ), era manifestamente baixo. Vinte anos depois, esta situação mantinha-se quase na mesma. De facto, em 1957-1958, registou-se uma subida para um valor ainda insignificante, $1,9 \mathrm{~kg} \mathrm{~K}_{2} \mathrm{O}$ ha-1, quando em Espanha, esse valor era de 4,4 $\mathrm{kg} \mathrm{K}_{2} \mathrm{O}$ ha $^{-1}$ e, na Holanda e Alemanha, era superior a 60 $\mathrm{kg} \mathrm{K}_{2} \mathrm{O}$ ha-1. É de salientar que já nessa altura se realizava experimentação de adubação com trigo e batata (Oliveira, 1960). Durante 30 anos (1929-1959), a grande maioria dos campos de ensaio localizava-se a sul do rio Tejo para a cultura do trigo (70\%), e a norte para a batata (78\%), sendo que as taxas médias de aplicação não foram além dos $37 \mathrm{~kg} \mathrm{~K} \mathrm{~K}_{2} \mathrm{O}$ ha $^{-1}$ no trigo, mas na batata atingiram $117 \mathrm{~kg} \mathrm{~K}_{2} \mathrm{O}$ ha $^{-1}$. Porém, enquanto as respostas ao $\mathrm{N}$ e $\mathrm{P}$ eram razoavelmente consistentes por região agrícola, as respostas ao $\mathrm{K}$ pelo trigo eram praticamente nulas (quando não negativas), mas as respostas ao $\mathrm{K}$ pela batata eram apreciáveis (Oliveira, 1960), particularmente na região Norte.

A ideia generalizada de que os solos do Baixo Alentejo eram genericamente bem abastecidos de $\mathrm{K}$ parece vir dos finais do século XIX. Fernandes (1899: pp. 180), referindo-se às análises químicas destes solos, efectuadas por Rebelo da Silva, escreveu: «O resumo deste notável trabalho foi que os dois principais tipos de terra submetidos à análise, galegas e barros pretos, tinham ambos potassa e 'cal' mais que suficiente.» Mais tarde, aquando da calibração do método de Riehm (extracção pelo lactato de amónio) para determinação do P e K 'assimiláveis', Almeida e Balbino (1960: pp. 41) concluem que a maioria dos solos do país é «bem dotada de potássio assimilável»1.

De igual modo, a análise dos resultados da experimentação realizada até ao fim dos anos 70 do século passado revela que a maioria dos solos em Portugal manifesta uma resposta fraca das culturas ao K, particularmente no Sul do país (Alves e Silva, 1958; Balbino, 1961, 1963a; Alves, 1965-1967; Alves e Cardoso, 1967; Alves et al., 1979). Só excepcionalmente foram observadas reacções positivas à adubação potássica em termos de acréscimos significativos da produtividade das culturas (Almeida, 1958; Mourão, 1960; Oliveira, 1960; Balbino, 1961; Alves, 1968; Alves et al., 1979; Marcelo, 2001, Jordão et al., 2003). Igualmente, as aplicações de $\mathrm{K}$ não produziram os efeitos esperados na subida das concentrações foliares de K ou nos órgãos reprodutivos (Brito, 1968; Jordão, 1990; Carranca et al., 1993). Os resultados da experimentação com certas culturas mostram que havia bastante perplexidade por parte dos investigadores quanto à adubação potássica, pois onde se esperariam respostas notórias à aplicação de $\mathrm{K}$ em termos de produtividade, devido às baixas concentrações iniciais de $\mathrm{K}$ nos solos e nas folhas, elas tardavam em surgir. Segundo Balbino (1961), no caso do trigo, era praticamente ponto assente que o $\mathrm{K}$ era dispensável na quase totalidade dos casos. Ao longo do tempo, houve várias tentativas para explicar a ausência de respostas das culturas ao K (Almeida, 1958), mas também havia quem entendesse que a reacção ao $\mathrm{K}$ não era evidente devido às baixas doses utilizadas (Balbino, 1961), o que limitaria a eficácia da sua aplicação.

Com o trabalho laboratorial de Gama (1961, 1963, 1966), iniciam-se os estudos sobre a fixação do K, particularmente nos solos do Sul de Portugal. Assim, Gama (1966, 1968) admitiu que a eficácia da adubação potássica podia ser limitada devido à fixação do $\mathrm{K}$ por certos solos e que esse processo devia ser considerado aquando das recomendações de adubação. Todavia, os estudos da fixação do K, iniciados por Gama, não tiveram nenhum seguimento, nem laboratorialmente nem em ensaios de campo. Os seus alertas (Gama, 1968) também não surtiram efeito em termos agronómicos. 
Tem-se constatado que a fraca resposta das culturas à adubação potássica pode dever-se às elevadas reservas de $\mathrm{K}$ facilmente mobilizáveis, existentes em certos solos (Portela, 1993), e/ou às baixas exigências de $\mathrm{K}$ de algumas culturas. Ou pode, ainda, atribuir-se à baixa eficácia da adubação potássica. Com efeito, a eficácia da aplicação do $\mathrm{K}$ pode ser acentuadamente reduzida devido à fixação do $\mathrm{K}$ ou, ainda, à existência de um outro factor limitante.

Aquando da avaliação da adubação potássica em ensaios de campo nos vários trabalhos, é comum surgirem apreciações do tipo: 'Os nossos solos continuam a não reagir ao potássio'; ou 'só se registaram acréscimos significativos de produção com a aplicação do nível mais elevado de potássio'; ou 'foram necessárias incorporações sucessivas de potássio'; ou ainda 'houve morosidade na resposta ao $\mathrm{K}^{\prime}$. Porém, a persistência da adição do $\mathrm{K}$ ao solo acabou por dar resultados na oliveira ao fim de 2 , 4, 8, 10 anos consecutivos da sua aplicação, como constataram Brito (1968), Jordão (1990) e Marcelo (2001). É manifesto, nestes casos, que o K adicionado ao solo não fica disponível para absorção pelas plantas, mas acaba por ser retido (fixado) na fase sólida do solo em formas pouco acessíveis às plantas. Com efeito, a aplicação de $\mathrm{K}$ a solos cujas reservas foram esgotadas neste nutriente resulta na sua fixação pela transferência do K da solução do solo para locais específicos dos espaços intercamada de alguns filossilicatos 2:1 (Rich, 1968; Mengel, 1985).

Neste artigo de revisão, foram tidos em conta os trabalhos iniciados no fim do século XIX, resultados de ensaios de campo realizados desde 1929 e os ensaios laboratoriais executados a partir da década de 50 do século XX. Além disso, também se avaliaram e consideraram: i) resultados empíricos obtidos em parcelas de agricultores; ii) relatórios internos do Ministério da Agricultura, de centros de investigação e de instituições de ensino superior; e, por fim, consideraram-se dados publicados e não publicados pertencentes às autoras do presente trabalho.

Neste trabalho, começa-se por fazer uma retrospectiva da experimentação realizada, na qual parece evidente a ineficácia da adubação potássica e a perplexidade revelada por diversos investigadores quanto à ausência de respostas das culturas à aplicação de K. Serão tidos em conta três aspectos relativos à fixação do K: capacidade de fixação do $\mathrm{K}$ de diversos solos e os factores que favorecem a fixação do K; os solos propícios à fixação do K, e ainda a reversibilidade da fixação do K. Por último, apresentam-se as conclusões mais relevantes e as ilações a retirar sob o ponto de vista agronómico. Finaliza-se com sugestões de algumas estratégias para corrigir a carência deste macronutriente, cuja importância para a produtividade das culturas é incontestável. Dada a variação dos sistemas de classificação dos solos de Portugal utilizados no presente trabalho, o que se traduz na dificuldade de utilização e uniformização da informação existente, usaram-se, sempre que possível, as classificações dos solos de Portugal (Cardoso, 1965, 1974), as legendas da FAO/Unesco (1988) e a WRB (2006) na identificação das unidades-solo.

\section{FIXAÇÃO DO POTÁSSIO NOS SOLOS}

Na Figura 1, apresentam-se as relações de equilíbrio entre as diversas formas do $\mathrm{K}$ existentes no solo. A taxa e o sentido das reacções indicam se o $\mathrm{K}$ existente em formas menos disponíveis é mobilizado para a solução, ou se o K aplicado ao solo será lixiviado para horizontes inferiores, absorvido pelas plantas ou convertido em formas mais disponíveis ou menos disponíveis. Assim, tendo em conta a localização/mobilidade do $\mathrm{K}$, podem distinguir-se várias fracções do K no solo: o K que faz parte da estrutura dos minerais primários (ex. feldspatos); o K existente no espaço intercamada dos filossilicatos 2:1, o qual não pode ser utilizado pelas plantas e que vários autores designam por 'K não permutável' ou por ' $\mathrm{K}$ fixado'; o $\mathrm{K}$ adsorvido maioritariamente nos locais de carga negativa localizados na superfície exterior dos filossilicatos, vulgarmente designado por $\mathrm{K}$ de troca ou permutável e, por último, o K em solução que está em equilíbrio instantâneo com o K em posição de troca. Note-se que não existem compartimentos estanques entre as diversas formas do $\mathrm{K}$ do solo, havendo sempre alguma sobreposição entre elas.

A planta e o solo formam um sistema dinâmico em permanente interacção. $\mathrm{O} \mathrm{K}$ em solução está imediatamente disponível para a planta, mas a sua concentração no solo é, em qualquer instante, 
demasiado baixa para fornecer à planta a quantidade suficiente do nutriente ao longo de todo o ciclo vegetativo. $\mathrm{O}$ reabastecimento da solução do solo a partir do K existente na fase sólida (adsorvido e no espaço intercamada) e a taxa a que este é mobilizado para a fase aquosa são importantes para manter um nível de $\mathrm{K}$ em solução adequado ao desenvolvimento das plantas. Como se pode observar na Figura 1, o equilíbrio entre o $\mathrm{K}$ em solução e o K fixado dá-se nos dois sentidos. $\mathrm{Ou}$ seja, o K pode ser libertado para a solução do solo a partir do espaço intercamada dos filossilicatos ou ser aí fixado por difusão da fase líquida para a fase sólida. Convencionou-se chamar a estes processos, respectivamente, 'libertação do $\mathrm{K}^{\prime}$ e 'fixação do K'

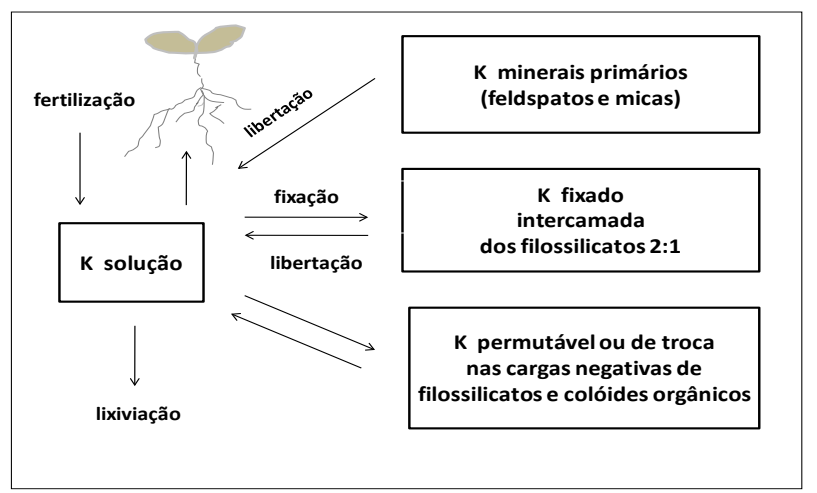

Figura 1 - Dinâmica do potássio no solo.

De um modo geral, a determinação do K fixado tem-se baseado na extração do $\mathrm{K}$ com acetato de amónio, sendo o $\mathrm{K}$ fixado calculado por diferença entre o potássio adicionado e a variação do K extraído por troca com o ião amónio, ou seja, o $\mathrm{K}$ fixado refere-se ao $\mathrm{K}^{+}$que não foi permutado com o $\mathrm{NH}_{4}^{+}$. Com efeito, quando se adicionam ao solo sais potássicos solúveis, parte do $\mathrm{K}$ fica nas formas solúvel e permutável, mas uma outra parte pode ser retida no espaço intercamada dos minerais 2:1 (ilites e micas alteradas, vermiculites, interestratificados e certas esmectites, como as de alta carga), ficando numa forma que não é extraível pelo acetato de amónio. O mecanismo de fixação do $\mathrm{K}$ tem sido descrito como uma retenção dos iões $\mathrm{K}^{+}$não hidratados no espaço intercamada, que estarão ligados aos oxigénios das cavidades ditrigonais existentes no plano basal das folhas tetraédricas das camadas 2:1 dos filossilicatos acima mencionados. A fixação do $\mathrm{K}$ no espaço intercamada atribui-se quer ao perfeito ajustamento do $\mathrm{K}$ às cavidades ditrigonais, quer à sua baixa energia de hidratação (Rich, 1968; Fanning et al., 1989). As referências à fixação do $\mathrm{K}$ pelas vermiculites e minerais micáceos são frequentes, enquanto as referentes às esmectites são mais raras. Segundo Borchardt (1989), a fixação do $\mathrm{K}$ em alguns solos ricos em esmectites será possível devido à presença de mica residual nestes filossilicatos. Também a presença, nos solos, dum tipo particular de esmectite (a beidelite) pode levar à fixação do $\mathrm{K}$, devido ao facto de uma parte considerável da sua carga se dever às substituições isomórficas que ocorrem nas folhas tetraédricas, levando a uma maior proximidade da carga negativa do plano basal da camada 2:1, determinando maior energia de ligação ao $\mathrm{K}^{+} \mathrm{e}$, deste modo, uma fixação mais intensa do catião. Posto isto, e relativamente aos objectivos deste estudo, o termo 'fixação do $K^{\prime}$ refere-se à retenção do $K$ entre as camadas colapsadas de filossilicatos do tipo 2:1, após a aplicação de K ao solo.

Os estudos sobre a fixação do $K$ têm dado ênfase, sobretudo, à fracção argila $(<2 \mu \mathrm{m})$ do solo. Porém, há muito se reconheceu que outras fracções granulométricas são igualmente relevantes e os artigos mais recentes (Murashkina et al., 2007a,b; Simonsson et al., 2009; Najafi-Ghiri e Abtahi, 2013) reforçaram esta ideia. Estes autores demonstraram que os produtos de meteorização dos minerais primários parcialmente alterados presentes nas fracções limo e areia fina desempenham um papel crucial na fixação do K no solo. Assim, os minerais responsáveis pela fixação do $\mathrm{K}$, naquelas três fracções granulométricas, são também as vermiculites, minerais micáceos como as ilites e as micas degradadas (micas abertas), certas esmectites e os minerais interestratificados ilite/vermiculite.

\section{OS SOLOS PORTUGUESES RESPONDEM, OU NÃO, AO POTÁSSIO? REFLEXÃO SOBRE A AVALIAÇÃO DA DISPONIBILIDADE DO POTÁSSIO NOS SOLOS}

São diversas as razões apontadas por alguns autores para a ausência de respostas das culturas à aplicação do $\mathrm{K}$ aos solos. Referindo-se ao baixo consumo de adubos potássicos em Portugal, Almeida (1958) atribui-o a vários motivos: ao facto 
de a maioria dos solos ser bem dotada de $\mathrm{K}$, aos fracos rendimentos unitários das culturas e ainda às baixas exigências das culturas ensaiadas. Mas, segundo Balbino (1961), também havia quem entendesse que a reacção ao K não era evidente, devido às baixas doses utilizadas. Por sua vez, Balbino et al. (1963) consideraram que as concentrações de $\mathrm{K}$ no solo eram suficientes para o nível das produções unitárias alcançadas pelo trigo (1500 kg ha-1) na região de Elvas, e, portanto, as doses aplicadas (50 e 100 kg K $\mathrm{K}_{2} \mathrm{O} \mathrm{ha}^{-1}$ ) não foram percepcionadas como baixas. Com efeito, o teor médio do $\mathrm{K}$ de troca nos solos da região de Elvas era classificado como alto (> $100 \mathrm{mg} \mathrm{K} \mathrm{kg-1)}$ e daí aqueles autores considerarem que era 'bastante', pelo menos em $50 \%$ dos casos (Alves e Silva, 1958). Por outro lado, estes autores admitiram que, em $29 \%$ dos casos, em que o $\mathrm{K}$ de troca era inferior àquele valor, se esperaria reacção das culturas ao $\mathrm{K}$.

A necessidade de emprego de maiores quantidades de adubos potássicos foi proposta por Almeida (1958). Mas note-se que este aumento foi condicionado pela necessidade de intensificação de outros factores de produção, como o $\mathrm{N}$ e $\mathrm{P}$, e não pelo carácter fixador de $\mathrm{K}$ de diversos solos. A natureza fixadora do solo parece bem patente no ensaio relatado por Almeida (1958). A resposta ao $\mathrm{K}$ por parte do trigo, embora só se tenha manifestado no segundo ano do ensaio, parece óbvia à luz do conhecimento actual. Por parte de Almeida, a interpretação do resultado no segundo ano foi no sentido de desconsiderar a resposta ao $\mathrm{K}$ (no tratamento NPK), apesar de o acréscimo de produtividade ter sido mais de quatro vezes superior ao tratamento NP, isto porque aquele autor não admitiu que o solo tivesse ficado exaurido em K no tratamento NP no segundo ano de ensaio, mas valorizou, sim, o ataque do trigo por uma doença criptogâmica. Ou seja, não atribuiu à má nutrição potássica do trigo a baixa produtividade do tratamento NP (isto é, K0), mas atribuiu-a a uma doença, levando mesmo o autor a desvalorizar o acréscimo de produção de $25 \%$ do primeiro para o segundo ano do ensaio no tratamento NPK. Com efeito, esta interpretação é algo surpreendente, pois revela que, à data, a má nutrição potássica das plantas ainda não era interpretada como potenciadora de doenças. Parece evidente deste ensaio que o K aplicado no primeiro ano terá sido fixado, mas a repetição da adubação potássica no segundo ano teve uma resposta positiva por ter permitido o aumento do nível do $\mathrm{K}$ disponível no solo, não só no tratamento NPK, como comparativamente ao tratamento NP, que, por sua vez, revela que as reservas de $\mathrm{K}$ do solo terão ficado esgotadas.

Além da cultura do trigo, também o centeio, a cevada e a aveia davam respostas reduzidas ao $\mathrm{K}$ em diversas zonas do Alentejo. Os ensaios de adubação potássica efectuados em 1965-1973 com aqueles cereais (Alves et al., 1979), para produções de 1500-2000 kg, não produziram acréscimos significativos na produção de grão quando as concentrações de $\mathrm{K}$ extraível no solo variaram entre 28 e $162 \mathrm{mg} \mathrm{kg}^{-1}$. Todavia, mais tarde, Alves (1984) também verificou que havia morosidade da resposta ao $\mathrm{K}$ por parte do trigo em certas unidades-solo. Tendo realizado uma adubação potássica ao trigo em Castro Verde (solos Px e $\mathrm{Pb})^{2}$, este autor verificou que o cereal continuou a responder à aplicação de $\mathrm{K}$ (150 kg ha-1 ano) após sete anos de adubação potássica (1973-1980). Além disso, o acréscimo de produção nos três últimos anos até foi dos mais elevados. Ou seja, a resposta ao K encontrava-se ainda na fase ascendente da curva. Por outro lado, o K extraível do solo subiu constantemente (de $25 \mathrm{mg} \mathrm{kg}^{-1}$ para $72 \mathrm{mg} \mathrm{kg}^{-1}$ de $\mathrm{K}$ ), sem que se tenha atingido uma concentração de K extraível, a partir da qual tivesse abrandado a resposta da cultura do trigo ao $\mathrm{K}$.

Os vários casos, reportados ao longo de três décadas, de respostas tardias aos adubos potássicos, particularmente em olival (através do aumento de produtividade ou das concentrações foliares de K), sugerem que haveria uma grande probabilidade de a morosidade da resposta à adubação ser devida à fixação do $\mathrm{K}$ pelo solo. Em 1935, as elevadas necessidades de K da oliveira para a produção de azeitona e as respostas do olival ao K eram conhecidas de Seabra. Em dois anos de um ensaio (1935-1936) instalado em Elvas, Seabra (1935) obteve, em média, um acréscimo de produção de azeitona de $675 \mathrm{~kg} \mathrm{ha}^{-1}$ com a aplicação de $125 \mathrm{~kg}$ de sulfato de potássio (52 kg K ha-1), o que originou a produção de $13 \mathrm{~kg}$ de azeitona por cada $\mathrm{kg}$ de $\mathrm{K}$ aplicado. Também em Elvas, Brito (1968) apenas obteve acréscimos significativos de produtividade de azeitona ao segundo ano num solo $\mathrm{Vc}^{2}$. Por outro lado, só conseguiu subir as concentrações foliares de 
$\mathrm{K}$ da oliveira acima do nível de deficiência após a aplicação de $200 \mathrm{~kg} \mathrm{~K}_{2} \mathrm{O}$ ha-1 durante dois anos (i. e. $400 \mathrm{~kg} \mathrm{~K}_{2} \mathrm{O} \mathrm{ha}^{-1}$ ), em solos de Beja $\left(\mathrm{Pc}^{\prime}, \mathrm{Bp}\right)^{2}$. De igual modo, Jordão (1990) só obteve subida da concentração foliar do $\mathrm{K}$ nas folhas dum ano na oliveira em Póvoa de Santarém (solos Vac e Pc) ${ }^{2}$ apenas no quarto ano da aplicação do $\mathrm{K}(0,5 \mathrm{~kg}$ $\mathrm{K}$ por árvore aplicado na forma de $\mathrm{KCl}$ ). De acordo com Marcelo (2001), as respostas à adubação potássica em olival só começaram a fazer-se sentir após oito anos consecutivos de aplicação de 67, 163 e $200 \mathrm{~kg} \mathrm{~K} \mathrm{ha}^{-1}$ ano $^{-1}$ num ensaio instalado em Elvas.

O quadro anteriormente descrito foi igualmente observado com outra fruteira por Carranca et al. (1993). Estes autores também não conseguiram, num laranjal de Setúbal, num solo $\mathrm{Aac}^{2}$, e após sete anos de aplicação de $250 \mathrm{~kg} \mathrm{~K} \mathrm{ha}^{-1} \mathrm{ano}^{-1}$, elevar as concentrações foliares de $\mathrm{K}$ além dos níveis de deficiência $\left(6,23 \mathrm{~g} \mathrm{~kg}^{-1}\right)$, nem produzir efeitos significativos na qualidade dos frutos, quando comparados com os obtidos com níveis de aplicação de $\mathrm{K}$ mais reduzidos.

É oportuno introduzir aqui uma reflexão sobre o método químico utilizado oficialmente para a avaliação da disponibilidade do $\mathrm{K}$ do solo para as plantas. No laboratório oficial português, o Laboratório Químico Agrícola Rebelo da Silva (LQARS), e antes dos anos 70 (séc. XX) era o $\mathrm{K}$ de troca o índice utilizado para avaliação da disponibilidade do K no solo, sendo o método em vigor na altura o do cloreto de bário-TEA (trietanolamina). Era com base neste método que, inicialmente (e antes da calibração do método de Egnér-Riehm) se decidia da necessidade de adubação potássica (Alves e Silva, 1958) e se esboçaram as primeiras classes de fertilidade do solo para a cultura do trigo.

A calibração do método de Riehm (mais tarde designado por Egnér-Riehm) com vista ao estabelecimento das classes de fertilidade do solo para o $\mathrm{K}$ terá sido efectuada durante os anos 50 do século passado, tendo esse trabalho sido publicado no fim dessa década por Almeida e Balbino (1960). Com efeito, a extracção do K com uma mistura de lactato de amónio e ácido acético a pH 3,7 produziu a melhor correlação com os ensaios experimentais em vaso, segundo o método de Mitscherlich, tendo a cevada como planta-teste, tanto em solos derivados de calcários como nos solos derivados de materiais não calcários. Os solos testados eram sobretudo do Sul do país e, no final, foram classificados quanto ao K dito 'assimilável' em cinco categorias: de muito pobres a muito ricos, de acordo com a sua produção relativa (produção com aplicação NPx100/produção com aplicação NPK).

A calibração do método de Egnér-Riehm foi posteriormente efectuada por Balbino (1963b) com o trigo, tanto em ensaios em vaso como em ensaios de campo. O autor agrupou os solos testados em três classes de fertilidade para o $\mathrm{K}$ : baixo, com $<50 \mathrm{mg} \mathrm{kg}^{-1}$ de $\mathrm{K}_{2} \mathrm{O}$; médio, com 51-100 mg kg-1 de $\mathrm{K}_{2} \mathrm{O}$; e alto, com $>100 \mathrm{mg} \mathrm{kg}^{-1}$ de $\mathrm{K}_{2} \mathrm{O}$. Os solos pobres correspondiam a uma produção relativa de $70 \%-80 \%$ e os ricos a uma produção relativa de $90 \%-95 \%$ e médio entre aqueles dois intervalos. Quando o $\mathrm{K}_{2} \mathrm{O}$ excedia $100 \mathrm{mg} \mathrm{kg}^{-1}$ (caso da maioria dos campos experimentais), a resposta ao K não era significativa. Note-se, porém, que Balbino (1963b) aclara que as classes estabelecidas se basearam apenas em ensaios em vaso, isto porque os ensaios de campo não mostravam respostas nítidas do trigo à adubação potássica. Portanto, aquelas classes deveriam ser tidas como provisórias e utilizadas com certas reservas. Analisando hoje os ensaios de campo, verifica-se que foram utilizados dois níveis de aplicação de $\mathrm{K}_{2} \mathrm{O}$ (50 e $\left.100 \mathrm{~kg} \mathrm{ha}^{-1}\right)$, o que corresponde a taxas de aplicação de $\mathrm{K}$ muito baixas (no máximo a $42 \mathrm{mg}$ de $\mathrm{K} \mathrm{kg}^{-1} \mathrm{de}$ solo), o que significa que, para solos fixadores de $K$, não é de esperar resposta ao $\mathrm{K}$.

O método de Egnér-Riehm foi adoptado em 1962 pelo laboratório da CUF (Companhia União Fabril) para a recomendação da adubação potássica (Balbino, 1968), mas durante a década de 60 (século XX) ainda se prosseguiu o estudo da calibração deste método, que visava uma melhor definição dos limites das classes de fertilidade. A sua adequação aos solos do país serviu de base à recomendação de Balbino (1968) no sentido de que o método de Egnér-Riehm se tornasse o método oficial português. Em 1974, Santos ainda se referia a três classes de fertilidade, todavia com limites diferentes para o 'K assimilável' dos mencionados por Balbino (1968), isto é: < $100 \mathrm{mg}$ de $\mathrm{K}_{2} \mathrm{O} \mathrm{kg}{ }^{-1}$, 100-200 mg de $\mathrm{K}_{2} \mathrm{O} \mathrm{kg}^{-1}$ e > $200 \mathrm{mg}$ de $\mathrm{K}_{2} \mathrm{O} \mathrm{kg}^{-1} \mathrm{com}$ a classificação de 'terras pobres', 'terras médias' e 'terras ricas', respectivamente. Mais tarde, o 
Laboratório Químico Agrícola Rebelo da Silva (Dias et al., 1980) viria a estipular as cinco classes de fertilidade do solo usadas em Portugal até aos dias de hoje: muito baixa $\leq 25 \mathrm{mg}$ de $\mathrm{K}_{2} \mathrm{O} \mathrm{kg}{ }^{-1}$, baixa 26-50 mg de $\mathrm{K}_{2} \mathrm{O} \mathrm{kg}^{-1}$, média 51-100 mg de $\mathrm{K}_{2} \mathrm{O} \mathrm{kg}^{-1}$, alta $101-200 \mathrm{mg}$ de $\mathrm{K}_{2} \mathrm{O} \mathrm{kg}^{-1}$ e muito alta $\geq 200 \mathrm{mg}$ de $\mathrm{K}_{2} \mathrm{O} \mathrm{kg}^{-1}$. Estas categorias foram estabelecidas de acordo com a probabilidade de ocorrência de resposta das culturas à aplicação do K. Genericamente, as classes baixas apresentavam elevada probabilidade de resposta ao K, enquanto nas classes altas a probabilidade de resposta seria reduzida. Estas classes foram inicialmente utilizadas para qualquer solo e cultura, mas têm vindo a ser aperfeiçoadas e ajustadas de acordo com as necessidades nutritivas próprias de certas culturas e de certos solos (LQARS, 2000).

Em última análise, a calibração do método de Egnér-Riehm, utilizado em rotina com vista à recomendação das adubações potássicas, baseou-se exclusivamente em ensaios em vaso e foi testado num número limitado de solos (cerca de $90 \%$ a sul do rio Tejo) e culturas. Como seria de esperar, estas classes não se ajustam a todo o tipo de cultura ou tipo de solo, havendo frequentemente discrepâncias nas respostas ao K. Por um lado, a planta-teste utilizada, o trigo, devido ao seu ciclo longo e ao tipo de sistema radicular (elevado comprimento e densidade radiculares) tem uma grande capacidade de explorar o $\mathrm{K}$ do solo, nomeadamente o K não permutável, o que se verifica tanto nas gramíneas, como nos cereais praganosos, ao passo que as culturas de ciclo curto, culturas industriais exigentes em $\mathrm{K}$, fruteiras e outras, com baixa densidade radicular e com absorção de K concentrada num lapso de tempo mais curto, exigem uma maior concentração de $\mathrm{K}$ na zona de expansão da raiz. Além disso, é de sublinhar que o poder tampão dos solos para o Ké muito variável, dependendo muito da textura e mineralogia dos solos e, portanto, da sua capacidade de manter o $\mathrm{K}$ em solução em níveis adequados ao crescimento das plantas. Por último, há que considerar o processo de fixação do K que ocorre em determinados solos do país, o que diminui muito a eficácia da adubação potássica, tornando aquelas classes de fertilidade inoperantes.

Terminado este parêntesis metodológico, retomemos o facto de que foi Gama, em 1961, que admitiu, pela primeira vez, que a fixação do K pudesse ocorrer em solos do Sul do país. Aparentemente, terá tentado obter uma explicação para as discrepâncias observadas nos estudos de Almeida e Balbino (1960) e, por isso, determinou a capacidade de fixação do $\mathrm{K}$ em vários solos do Alentejo (Gama, 1963, 1966). Gama (1966, 1968) sugere, pela primeira vez, que se tenha em conta a fixação do $\mathrm{K}$ em solos ávidos (elevada capacidade de fixação) de $\mathrm{K}$ (Pm, Pmg, Vx) ${ }^{2}$ no sentido de se melhorar a eficácia da adubação potássica. A polémica gerada à volta das respostas do trigo à aplicação de $\mathrm{K}$ levou Gama a fazer uma análise retrospectiva das respostas desta cultura à adubação potássica, fazendo uma inventariação dos tipos de solo onde seria expectável a resposta ao K (Gama, 1981).

No âmbito do aperfeiçoamento das recomendações de fertilização levadas a cabo pelo LQARS, a hipótese duma eventual retenção (leia-se: fixação) do $\mathrm{K}$ por certos solos foi admitida na sequência dos resultados experimentais de adubação potássica conduzidos no campo. Nestes casos, foi obtido empiricamente um factor de enriquecimento a ser considerado nas recomendações da adubação potássica, no sentido de se alcançar um índice de fertilidade do solo mais favorável às culturas. Assim, foi demonstrado que eram necessários, em média, cerca de $45 \mathrm{~kg} \mathrm{~K}_{2} \mathrm{O}$ ha $^{-1}$ para elevar as concentrações de $\mathrm{K}$ no solo em $10 \mathrm{mg} \mathrm{K}_{2} \mathrm{O} \mathrm{kg}^{-1}$, variando aquela quantidade entre 10 e $90 \mathrm{~kg} \mathrm{~K}_{2} \mathrm{O}$ ha $^{-1}$ de acordo com a natureza do solo (LQARS, 2000). Ora, com base nesta taxa de aplicação de potássio, é possível fazer uma estimativa da capacidade de fixação do $\mathrm{K}$, a qual tem um valor de $55 \%$. Porém, se a necessidade de aplicação de $\mathrm{K}$ for dupla daquela (isto é, $90 \mathrm{~kg} \mathrm{ha}^{-1}$ de $\mathrm{K}_{2} \mathrm{O}$ ), como terá ocorrido em certas unidades-solo, então a capacidade de fixação do K subirá para $78 \%$.

Já em 1989, Jordão, tendo em conta o trabalho experimental realizado em olival, tinha proposto o reajustamento das classes de fertilidade do solo para níveis de aplicação de $\mathrm{K}$ em olival para valores $25 \%$ superiores aos propostos anteriormente, em solos contendo carbonatos e em solos de textura fina (Jordão, 1989). Mais tarde, Jordão et al. (2003) vêm a reconhecer que a fixação do K pelo solo explicaria a necessidade de adicionar taxas elevadas de K, como foi o caso da aplicação de 1330 
$\mathrm{kg} \mathrm{K} \mathrm{ha-1} \mathrm{em} \mathrm{ensaios} \mathrm{de} \mathrm{fertilização} \mathrm{da} \mathrm{oliveira} \mathrm{na}$ Herdade dos Soidos (Santarém) em solos $\mathrm{Bc}^{2}$ e $\mathrm{Pc}^{2}$ (Vertissolo Êutrico e Regossolo Calcárico Êutrico, respectivamente). Segundo os autores, a dominância de minerais do grupo dos filossilicatos $2: 1$ como a vermiculite $(<10 \%)$, ilite $(10 \%-20 \%)$ e esmectite $(20 \%-40 \%)$, poderiam explicar a fixação do $\mathrm{K}$ e, por isso, os acréscimos significativos de produção no olival só ocorrerem com a aplicação do nível mais elevado de $\mathrm{K}$.

Entretanto, o trabalho experimental de Marcelo et al. (2005) na região do Alto Alentejo (Elvas), em terrenos calcários de unidades-solo $\mathrm{Pc}^{\prime 2}$ e $\mathrm{Vc}^{2}$ (Cambissolos Calcários e Cambissolos Cromocalcários, respectivamente), levaram a uma estimativa do factor de enriquecimento do solo para a camada superficial de 5,3 $\mathrm{kg} \mathrm{K} \mathrm{ha}^{-1}$ para aumentar o $\mathrm{K}$ extraível de $1 \mathrm{mg} \mathrm{K} \mathrm{kg} \mathrm{Kg}^{-1}$ de solo, valor este da mesma ordem de grandeza do proposto anteriormente pelo LQARS (2000). Após efectuar os cálculos adequados, este factor de enriquecimento corresponde a uma capacidade de fixação do $\mathrm{K}$ destes solos estimada em $60 \%$. A estimativa de Marcelo et al. (2005) teve como base a necessidade de adicionar $\mathrm{K}$ à taxa de $2000 \mathrm{~kg} \mathrm{ha}^{-1}$, isto é, houve necessidade de aplicar $200 \mathrm{~kg} \mathrm{~K} \mathrm{ha}{ }^{-1}$ durante 10 anos para que se viesse a verificar enriquecimento do solo em $\mathrm{K}$ até atingir um índice de fertilidade considerado adequado pelos autores. Tendo em conta a produção do olival, os autores estimaram em $780 \mathrm{~kg} \mathrm{~K} \mathrm{ha-1}$ a quantidade de $\mathrm{K}$ retido (fixado) pelo solo até à profundidade de $50 \mathrm{~cm}$.

Em suma, embora não tendo sido obtida laboratorialmente pelo LQARS a determinação da capacidade de fixação do $\mathrm{K}$ de certos solos, foi alcançada empiricamente uma estimativa desse valor. Notese, porém, que não se especificaram as respectivas unidades-solo.

\section{CAPACIDADE DE FIXAÇÃO DO POTÁSSIO DOS SOLOS PORTUGUESES}

Nesta secção registam-se vários casos em que são manifestos os indícios de se estar perante solos fixadores de K. Aqui também se analisam os trabalhos laboratoriais executados depois de 1950, com vista à identificação de solos fixadores de $\mathrm{K}$, e se inventariam os factores considerados relevantes na fixação do K: por exemplo a secagem das amostras de solos, o pH, a textura, e a mineralogia dos solos. Por fim, expõem-se os resultados do trabalho experimental das autoras do presente artigo e que constam de dois estudos nos quais o carácter fixador dos solos foi avaliado.

\section{Indícios da fixação do potássio}

O artigo de Oliveira (1960), em que o autor fez o apuramento estatístico dos ensaios de adubação que decorreram entre 1929 e 1959 em Portugal, revela que é evidente a ausência de resposta do trigo ao K. Devido à taxa média de aplicação de $\mathrm{K}$ ter sido baixa (31 $\mathrm{kg} \mathrm{K} \mathrm{ha}^{-1}$ ) e apesar das razões já referidas anteriormente por Almeida (1958) para a ausência de respostas ao $\mathrm{K}$, admite-se a possibilidade de o $\mathrm{K}$ ter sido fixado quase na sua totalidade, já que, de entre os solos do Sul, existe um conjunto de unidades-solo com elevada capacidade de fixação do K. Com efeito, a tomada de decisões quanto à instalação dos 232 campos de ensaio da cultura do trigo baseou-se no tipo de solos (embora, à data, não existisse classificação sistemática dos solos do país) e nas práticas de fertilização antecedentes (Oliveira, 1960). Por conseguinte, é muito provável que se tenham submetido à adubação potássica quer solos que dispensavam a adição do $\mathrm{K}$, quer solos fixadores de $\mathrm{K}$.

No entanto, e relativamente à oliveira, já não se passaria o mesmo. Num pequeno livro de divulgação destinado a agricultores, Seabra (1935: pp. 53), reportando-se às necessidades da oliveira, afirmava que «a oliveira requer muito anidrido fosfórico, muita potassa, discreta quantidade de cal e azoto em quantidade suficiente». Quanto à taxa de adubo potássico a aplicar (cloreto ou sulfato de potássio), Seabra recomendava valores da ordem de $250-300 \mathrm{~kg} \mathrm{ha}^{-1}$ para 100-150 oliveiras. Tendo em conta estas taxas de aplicação de adubo (125-150 kg $\left.\mathrm{K} \mathrm{a}^{-1}\right)$, não há dúvida de que estão muito acima das praticadas, à data, na cultura do trigo (31 kg K ha-1; Oliveira, 1960), ou mesmo das observadas noutros países e noutras culturas no mesmo período, como, por exemplo, os $38 \mathrm{~kg} \mathrm{~K} \mathrm{ha}^{-1}$ aplicados, em média, na Holanda por superfície agrícola útil (Graça, 1939). Com efeito, aquela recomendação parece ser copiosa, sugerindo a hipótese de que certos solos onde cresciam oliveiras careciam dessas elevadas 
taxas de adubação potássica, para que a cultura fosse rentável.

Ensaios experimentais conduzidos por Brito (1968) no Alto Alentejo, em solos derivados de calcários, permitiram verificar que só após a aplicação de $167 \mathrm{~kg} \mathrm{~K} \mathrm{ha}{ }^{-1}$, durante dois anos num solo $\mathrm{Pc}^{\prime 2}$ de Elvas, as concentrações foliares de $\mathrm{K}$ da oliveira ultrapassaram o nível de deficiência. Numa outra unidade-solo, mas agora num $\mathrm{Vc}^{2}$ após dois anos de

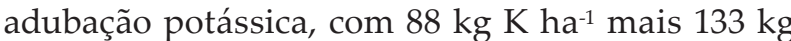
$\mathrm{K} \mathrm{a}^{-1}$ aplicado através do estrume, foi possível obter acréscimo de produção em outro olival. Do mesmo modo, Marcelo (2001) só obteve diferenças significativas na produção de azeitona nas mesmas unidades solo $\left(\mathrm{Pc}^{\prime} \text { e } \mathrm{Vc}\right)^{2}$ de Elvas (Herdade do Reguengo) após oito anos de aplicação sucessiva do adubo potássico nas taxas de 0-67-133-200 kg K ha-1.

Os ensaios conduzidos na Herdade de Longos (Campo Branco), localizada no concelho de Castro Verde, revelaram que nas unidades-solo $\mathrm{Px}^{2}$ e $\mathrm{Pb}^{2}$, mesmo ao sétimo ano de adubação potássica ao trigo (150 kg K ha-1 ano), a resposta ao K se encontrava ainda na fase ascendente da curva (Alves, 1984). A estranheza do autor pelo baixo acréscimo de $\mathrm{K}$ extraível do solo (8,5 $\mathrm{mg} \mathrm{K}_{2} \mathrm{O} \mathrm{kg}{ }^{-1}$ por ano), devido à aplicação de adubos potássicos, sustenta a hipótese de estes solos terem fixado o K. Com efeito, o autor realçou que apenas $17 \%$ do $\mathrm{K}$ anualmente aplicado ficara disponível no solo. Uma adubação potássica 'liberal' por mais algum tempo foi mesmo recomendada. Segundo Alves (1984), estas unidades-solo seriam representativas das culturas de trigo e de aveia, e estendendo-se por uma vasta área entre Aljustrel e até para lá de Almodôvar.

Gama (1988), ao estudar, durante sete anos, o efeito da adição anual de K (125 kg ha-1) sobre a evolução dos teores de $\mathrm{K}$ de troca num solo $\mathrm{Aac}^{2}$ num laranjal de Setúbal (Quinta da Várzea), constatou que houve um acréscimo muito lento daquele parâmetro na camada superficial, mas particularmente nas camadas $25-50 \mathrm{~cm}$ e $50-75 \mathrm{~cm}$. Também verificou que a subida do $\mathrm{K}$ de troca da primeira camada só se iniciou ao fim de três anos de ensaio e que havia uma mobilidade muito reduzida do $\mathrm{K}$ ao longo do perfil, mesmo ao cabo de sete anos. Ou seja, o K aplicado na forma de adubo teria sido quase todo retido neste horizonte. Além disso, a hipótese duma maior fixação do $\mathrm{K}$ nas camadas mais profundas também poderia ter ocorrido, como mostraram Shaviv et al. (1985) e Murashkina et al. $(2007 \mathrm{a}, \mathrm{b})$. A dominância de vermiculite e ilite neste solo justificariam plenamente a fixação do $\mathrm{K}$ em qualquer das três camadas em apreço.

Marcelo et al. (2011) avaliaram num olival o efeito da adubação potássica, feita através da rega, nas concentrações do $\mathrm{K}$ permutável em diversas profundidades, tendo verificado que houve um acréscimo significativo do $\mathrm{K}$ nas camadas $0-20 \mathrm{~cm}$ e 20-40 cm. O ensaio decorreu durante dois anos e foi instalado em solos $\mathrm{Cpc}^{2}$ e $\mathrm{Pcx}^{2}$ (Vertissolos e Calcissolos, respectivamente) da Herdade de Lameirões (Safara, Moura). Os autores concluíram que o $\mathrm{K}$ adicionado ficou, sobretudo, no horizonte superficial, havendo poucos indícios do seu transporte para profundidades abaixo dos $40 \mathrm{~cm}$. Porém, presume-se que, além do enriquecimento do solo em $\mathrm{K}$ permutável, existe a possibilidade de parte do $\mathrm{K}$ adicionado ter ficado fixado nas camadas mais superficiais do perfil do solo. Não se exclui a possibilidade de, no caso de algum transporte do $\mathrm{K}$, ter ocorrido fixação do elemento nas camadas mais profundas $(>40 \mathrm{~cm})$, isto na medida em que a capacidade de fixação do $\mathrm{K}$ tende a aumentar com a profundidade, como o mostraram Shaviv et al. (1985) e Murashkina et al. (2007a,b). Com efeito, as reservas de $\mathrm{K}$ das camadas mais inferiores do solo podem ser igualmente esgotadas quando a exportação de K pelas culturas não é compensada pela adubação potássica. Kuhlman (1990), por exemplo, demonstrou que os horizontes mais profundos do solo $(>30 \mathrm{~cm}$ ) podem fornecer, em média, $34 \%$ do $\mathrm{K}$ total absorvido pelo trigo num intervalo de $9 \%-70 \%$. Até à data, não se identificou nenhum estudo em Portugal em que se tenha determinado a fixação do $\mathrm{K}$ nos sucessivos horizontes do perfil do solo.

\section{Ensaios laboratoriais de fixação do potássio. Factores que afectam a fixação do $\mathrm{K}$}

Os ensaios laboratoriais para determinação da capacidade de fixação do $\mathrm{K}$ nos solos foram iniciados, na década de 60 do século passado, por Gama $(1961,1963,1966)$ em solos do Sul do país. À data, Gama (1963) sugeria, como factores determinantes da fixação do K pelos solos, a sua composição mineralógica, sobretudo a da fracção argilosa 
e, como condicionantes da intensidade da fixação para um mesmo solo, o quantitativo de $\mathrm{K}$ adicionado, a secagem das amostras, o $\mathrm{pH}$ e os catiões adsorvidos no complexo de troca.

Gama (1961) determinou a capacidade de fixação utilizando o acetato de amónio como solução extractante e vários ciclos de humedecimento e secagem em amostras de solos do Alentejo (Pmg, $\mathrm{Pm}, \mathrm{Vc}$ e $\mathrm{Bvc})^{3}$, que sujeitou a ensaios de incubação, após a aplicação de doses sucessivas de K. A capacidade de fixação variou entre 300 e $854 \mathrm{mg}$ de $\mathrm{K} \mathrm{kg}^{-1}$ de solo, sendo o solo Pm o mais fixador. O autor constatou que a capacidade de fixação do $\mathrm{K}$ aumentou com as taxas de $\mathrm{K}$ aplicadas. Os valores obtidos para aqueles solos foram, respectivamente, de 107, 526, 123 e $218 \mathrm{mg} \mathrm{de} \mathrm{K} \mathrm{kg}^{-1}$ para a taxa mais elevada de aplicação (105 mg de $\mathrm{K} \mathrm{kg}^{-1}$ de solo, o que corresponde à aplicação de 2083 kg K ha-1). Apesar de os solos Pm e Pmg fixarem quantidades de $\mathrm{K}$ muito distintas, foram os que, em termos percentuais, fixaram mais $\mathrm{K}$. A percentagem de fixação diminuiu com o K aplicado no solo Pmg, e manteve-se bastante constante nos outros três solos, não havendo indícios de que estivesse próxima a capacidade máxima de fixação do $\mathrm{K}$ nestes solos. O solo Pm foi o mais fixador, ou seja, cerca de $70 \%$ do $\mathrm{K}$ adicionado nos primeiros três níveis de aplicação foi fixado, e depois baixou gradualmente para os $50 \%$. O teor de argila dos solos não se correlacionou nem com a quantidade, nem com a percentagem de $\mathrm{K}$ fixado. Assim, aquele investigador concluiu que o solo $\mathrm{Pm}$, sendo ávido de $K$, não poderia satisfazer, de forma adequada, as necessidades de $\mathrm{K}$ duma cultura de ciclo curto e com exigências elevadas deste nutriente. A razão que terá levado Gama a seleccionar aquelas unidades-solo parece residir no facto de os ensaios de campo com o trigo terem dado respostas surpreendentes à adubação potássica, como parecem indiciar os relatos e os trabalhos efectuados naquele período por Oliveira (1960), Almeida e Balbino (1960), Balbino (1961) e Balbino et al. (1963). Mais tarde, Gama (1966) avaliou o efeito da secagem ao ar das amostras na fixação do $\mathrm{K}$ em solos de oito unidades-solo (Pg, Vc, Bpc, Bvc, Pmg, Px, Pm e $\mathrm{Vx})^{4}$, quatro delas já incluídas em trabalho anterior. As amostras destes solos foram sujeitas a um mês de incubação seguida de secagem ao ar, método que passou a ser vulgarmente aceite para determinar a capacidade de fixação do $\mathrm{K}$ dos solos.
Neste estudo, foi feita a análise termodiferencial da fracção argila para identificação dos minerais argilosos dominantes. De entre os resultados obtidos, destacam-se os seguintes:

1. A secagem ao ar das amostras de solo promoveu um acréscimo na fixação do $\mathrm{K}$ de $20 \%-30 \%$, excepto no solo Pg.

2. Os solos mais fixadores de $\mathrm{K}$ foram $\mathrm{Pm}$, Pmg e Vx. O solo Pm fixou $57 \%$ e $85 \%$ do K sob condições de humidade e secura, respectivamente.

3. A ilite seria o mineral argiloso responsável pela fixação do $\mathrm{K}$ em todos os solos, excepto nos barros (Bpc e Bvc) e, no caso do solo Pm, tratar-se-ia de ilite degradada.

4. Os solos com maior teor em argila (Bpc e Bvc) e $\mathrm{pH}$ alcalino, com argila dominantemente do tipo esmectite, fixaram muito pouco $\mathrm{K}$ no estado húmido.

A maioria dos estudos respeitantes ao efeito da secagem das amostras de solo na fixação do K corrobora os resultados obtidos por Gama (1966). Mas, em contraste, Cook e Hutcheson (1960), bem como Dowdy e Hutcheson (1963), referem que solos com um nível inicial elevado de $\mathrm{K}$ de troca fixam o Kapós secagem, ao passo que aqueles que possuem baixos níveis de $\mathrm{K}$ de troca se comportam de modo inverso. Segundo estes autores, é ainda possível que a fixação e a libertação do $\mathrm{K}$ possam ocorrer simultaneamente no mesmo solo após secagem, se os minerais argilosos forem misturas de ilite e de minerais expansíveis. A ilite seria responsável pela libertação do $\mathrm{K}$ e os minerais do grupo das vermiculites e algumas esmectites pela fixação do K. Mas também, e segundo aqueles autores, a secagem pode levar à fixação do $\mathrm{K}$ nos locais dos espaços intercamada adjacentes aos rebordos do cristal e, simultaneamente, o K pode ser libertado devido à exfoliação do rebordo do mineral provocada pela secagem. Assim, uma ou outra situação poderá ocorrer quando se seca o solo, dependendo do processo predominante. Também Goulding (1987) indica que o humedecimento e secagem podem, por simples efeito físico, aumentar a fixação do K, induzindo o colapso do espaço intercamada, ou podem permitir a libertação do K por rotura das partículas dos minerais. 
Quadro 1 - Propriedades físico-químicas dos solos do NE de Portugal (adaptado de Portela, 1993)

\begin{tabular}{|c|c|c|c|c|c|c|c|c|c|c|c|c|c|}
\hline \multirow[t]{2}{*}{ Solos } & \multicolumn{4}{|c|}{ Granulometria $\left(\mathrm{g} \mathrm{kg}^{-1}\right)^{\mathrm{a}}$} & \multirow{2}{*}{$\begin{array}{c}\mathrm{MO}^{\mathrm{b}} \\
\mathrm{g} \mathrm{kg}^{-1}\end{array}$} & \multirow{2}{*}{$\begin{array}{l}\mathrm{pH}^{\mathrm{c}} \\
\mathrm{H}_{2} \mathrm{O}\end{array}$} & \multicolumn{6}{|c|}{ Catiões permutáveis $\left(\mathrm{cmol}_{\mathrm{c}} \mathrm{kg}^{-1}\right)^{\mathrm{d}}$} & \multirow{2}{*}{$\begin{array}{c}\text { Kexe }^{\mathrm{e}} \\
\text { mgkg- }^{-1}\end{array}$} \\
\hline & AG & AF & $\mathbf{L}$ & Arg & & & $\mathrm{Ca}$ & Mg & K & $\mathrm{Na}$ & $\mathrm{H}+\mathrm{Al}$ & CTCe & \\
\hline 1 & 440 & 355 & 133 & 72 & 10 & 5,5 & 1,23 & 0,17 & 0,18 & 0,03 & 1,34 & 2,96 & 123 \\
\hline 6 & 294 & 481 & 160 & 65 & 5 & 5,5 & 1,39 & 0,11 & 0,11 & 0,03 & 0,97 & 2,61 & 78 \\
\hline 15 & 400 & 398 & 115 & 87 & 30 & 5,4 & 1,35 & 0,40 & 0,10 & 0,07 & 0,86 & 2,80 & 91 \\
\hline 9 & 447 & 291 & 155 & 106 & 9 & 6,1 & 3,05 & 0,27 & 0,17 & 0,03 & 0,16 & 3,65 & 96 \\
\hline 10 & 443 & 300 & 148 & 105 & 6 & 5,1 & 4,09 & 1,58 & 0,16 & 0,07 & 1,70 & 7,60 & 104 \\
\hline 2 & 102 & 435 & 377 & 86 & 6 & 6,5 & 7,66 & 2,20 & 0,10 & 0,08 & 0,70 & 10,75 & 65 \\
\hline 4 & 168 & 409 & 324 & 98 & 7 & 7,3 & 8,07 & 0,54 & 0,12 & 0,08 & 0,12 & 8,91 & 80 \\
\hline 8 & 476 & 309 & 127 & 88 & 5 & 5,7 & 4,34 & 1,81 & 0,21 & 0,07 & 0,07 & 8,33 & 106 \\
\hline 17 & 116 & 517 & 269 & 98 & 7 & 5,5 & 2,14 & 0,20 & 0,25 & 0,03 & 0,86 & 3,49 & 159 \\
\hline 11 & 306 & 311 & 303 & 80 & 10 & 5,5 & 0,71 & 0,18 & 0,19 & 0,03 & 1,39 & 2,50 & 147 \\
\hline 18 & 171 & 425 & 303 & 101 & 11 & 5,5 & 3,52 & 1,07 & 0,16 & 0,05 & 1,19 & 6,03 & 135 \\
\hline 19 & 201 & 414 & 275 & 110 & 14 & 5,4 & 1,92 & 0,33 & 0,43 & 0,05 & 1,05 & 3,81 & 312 \\
\hline 20 & 247 & 390 & 240 & 123 & 8 & 5,3 & 1,73 & 0,43 & 0,16 & 0,04 & 1,24 & 3,60 & 100 \\
\hline 12 & 111 & 570 & 161 & 155 & 18 & 6,5 & 5,64 & 5,60 & 0,21 & 0,04 & 0,16 & 11,62 & 131 \\
\hline 13 & 156 & 386 & 184 & 273 & 17 & 6,4 & 11,06 & 6,00 & 0,11 & 0,18 & 0,23 & 17,58 & 81 \\
\hline 14 & 184 & 425 & 263 & 129 & 11 & 6,1 & 5,44 & 2,72 & 0,08 & 0,09 & 0,30 & 8,63 & 55 \\
\hline 5 & 138 & 458 & 318 & 88 & 6 & 5,3 & 1,48 & 0,28 & 0,15 & 0,07 & 3,11 & 5,09 & 90 \\
\hline 16 & 132 & 584 & 205 & 78 & 125 & 4,7 & 0,40 & 0,30 & 0,18 & 0,05 & 3,11 & 4,02 & 90 \\
\hline 7 & 99 & 602 & 191 & 108 & 7 & 5,2 & 1,01 & 0,18 & 0,11 & 0,03 & 0,87 & 2,22 & 85 \\
\hline
\end{tabular}

AG- areia grossa; AF- Areia fina; L- limo; Arg- argila; MO- matéria orgânica; CTCe- capacidade de troca catiónica efectiva; Kex- K extraível.

a- método da pipeta; b- oxidação com $\mathrm{K}_{2} \mathrm{Cr}_{2} \mathrm{O}_{7}$; c- razão solo/solução de 1:2,5; d- solução $1 \mathrm{M}$ de acetato de amónio $\mathrm{pH} 7$ e o $\mathrm{H}+\mathrm{Al}$ pelo método $\mathrm{KCl} 1 \mathrm{M}$; e- método colorimétrico após extracção com lactato de amónio - ácido acético a pH 3,7.

Os estudos de fixação do K em Portugal só voltariam a ser efectuados 20 anos depois, por Portela (1989) em 20 solos da região de Alto Trás-osMontes e Douro, no âmbito dum trabalho com vista à avaliação da disponibilidade do $\mathrm{K}$ em solos do Nordeste (NE) de Portugal. A caracterização dos solos quanto às propriedades físicas e químicas consta do Quadro 1 e a análise mineralógica da argila, limo e areia fina encontram-se em Portela (1989, 1993). Com base nos dados apresentados naqueles dois estudos e após o cálculo da fixação do K, conforme Gama (1961, 1963), elaborou-se o Quadro 2. Neste quadro, as unidades-solo estão designadas de acordo com a classificação da legenda da FAO/Unesco de 1988 (AgroconsultoresCoba, 1991), estando os solos sequenciados de acordo com o material originário. Os solos são sobretudo derivados de rochas dominantes naquela região: granitos, filitos e micaxistos, embora se tenham incluído também solos desenvolvidos sobre corneanas, peridotitos, rochas xistosas ricas em minerais ferromagnesianos e sedimentos vários. Os solos objecto de estudo são, geralmente, de textura franco-arenosa, com baixos teores de argila, pH ácido e com baixas concentrações de K de troca (Quadro 1).

No Quadro 2, apresenta-se a capacidade de fixação do $\mathrm{K}\left(\mathrm{mg} \mathrm{kg}^{-1}\right)$ para a taxa máxima de aplicação de $\mathrm{K}$ e o valor médio da \% de fixação do K. Aquela taxa teve em conta a capacidade de troca catiónica e a textura dos solos. A capacidade de fixação do $\mathrm{K}$ do solo foi determinada através da equação:

$\mathrm{K}$ fixado $=\mathrm{K}$ aplicado $+\mathrm{K}$ permutável inicial $\mathrm{K}$ permutável após o tratamento. Também se incluiu neste quadro o K libertado [( $\mathrm{K}$ não permutável libertado pelo cultivo intensivo de azevém, em Portela (1993)].

Dos resultados alcançados e constantes do Quadro 2 destacam-se os seguintes:

1. Seis solos eram deficitários em $\mathrm{K}$ (solos 5, 7, 13, $14,15,16)$, mas quatro destes não são susceptíveis de fixarem o $\mathrm{K}$ (solos 5, 14, 15, 16). Apenas o solo 13 fixou uma quantidade assinalável; 
Quadro 2 - Potássio libertado pelo cultivo intensivo de azevém, K fixado e quantidade máxima de K aplicada a solos do NE de Portugal (adaptado de Portela, 1989, 1993)

\begin{tabular}{|c|c|c|c|c|}
\hline Solos & $\begin{array}{l}\text { Classificação dos solos (FAO/Unesco 1988), rocha de } \\
\text { substrato }\end{array}$ & $\begin{array}{l}\text { K libertado e } \\
\text { K fixado }\end{array}$ & & $\begin{array}{l}\text { K máximo } \\
\text { adicionado } \\
\left(\mathrm{mg} \mathrm{kg}^{-1}\right)\end{array}$ \\
\hline $\begin{array}{l}1 \text { Carrazeda } \\
\text { de Ansiães }\end{array}$ & Cambissolo Húmico de granitos alcalinos & $\begin{array}{l}\mathrm{K} \text { libertado }\left(\mathrm{mg} \mathrm{kg}^{-1}\right) \\
\mathrm{K} \text { fixado }\left(\mathrm{mg} \mathrm{kg}^{-1}\right) \\
\text { K fixado médio }(\%)\end{array}$ & $\begin{array}{r}227 \\
40 \\
53\end{array}$ & 75 \\
\hline $\begin{array}{l}6 \text { Peredo da Bemposta, } \\
\text { Miranda do Douro }\end{array}$ & Cambissolo Dístrico de granitos alcalinos & $\begin{array}{l}\mathrm{K} \text { libertado }\left(\mathrm{mg} \mathrm{kg}^{-1}\right) \\
\mathrm{K} \text { fixado }\left(\mathrm{mg} \mathrm{kg}^{-1}\right) \\
\text { K fixado médio }(\%)\end{array}$ & $\begin{array}{r}408 \\
39 \\
51 \\
\end{array}$ & 75 \\
\hline 15 Santo André, Montalegre & Cambissolo Húmico de granitos alcalinos & $\begin{array}{l}\text { K libertado }\left(\mathrm{mg} \mathrm{kg}^{-1}\right) \\
\text { K fixado }\left(\mathrm{mg} \mathrm{kg}^{-1}\right) \\
\text { K fixado médio }(\%)\end{array}$ & $\begin{array}{l}81 \\
22 \\
18\end{array}$ & 100 \\
\hline 9 Malhadas, Miranda do Douro & Alissolo Háplico de granitos cálcicos & $\begin{array}{l}\mathrm{K} \text { libertado }\left(\mathrm{mg} \mathrm{kg}^{-1}\right) \\
\mathrm{K} \text { fixado }\left(\mathrm{mg} \mathrm{kg}^{-1}\right) \\
\text { K fixado médio }(\%)\end{array}$ & $\begin{array}{r}193 \\
34 \\
43 \\
\end{array}$ & 100 \\
\hline 10 Miranda do Douro & Cambissolo Dístrico de granitos cálcicos & $\begin{array}{l}\mathrm{K} \text { libertado }\left(\mathrm{mg} \mathrm{kg}^{-1}\right) \\
\mathrm{K} \text { fixado }\left(\mathrm{mg} \mathrm{kg}^{-1}\right) \\
\text { K fixado médio (\%) }\end{array}$ & $\begin{array}{r}689 \\
18 \\
13\end{array}$ & 100 \\
\hline $\begin{array}{l}2 \text { Quinta do Carrascal, } \\
\text { Torre de Moncorvo }\end{array}$ & Cambissolo Êutrico de micaxistos & $\begin{array}{l}\text { K libertado }\left(\mathrm{mg} \mathrm{kg}^{-1}\right) \\
\mathrm{K} \text { fixado }\left(\mathrm{mg} \mathrm{kg}^{-1}\right) \\
\text { K fixado médio }(\%)\end{array}$ & $\begin{array}{r}925 \\
157 \\
74 \\
\end{array}$ & 200 \\
\hline 4 Muxagata, Vila Nova de Foz Côa & Luvissolo Háplico de micaxistos & $\begin{array}{l}\text { K libertado }\left(\mathrm{mg} \mathrm{kg}^{-1}\right) \\
\mathrm{K} \text { fixado }\left(\mathrm{mg} \mathrm{kg}^{-1}\right) \\
\text { K fixado médio }(\%)\end{array}$ & $\begin{array}{r}966 \\
122 \\
66 \\
\end{array}$ & 200 \\
\hline 8 Sendim, Miranda do Douro & Leptossolo Êtrico de micaxistos & $\begin{array}{l}\mathrm{K} \text { libertado }\left(\mathrm{mg} \mathrm{kg}^{-1}\right) \\
\mathrm{K} \text { fixado }\left(\mathrm{mg} \mathrm{kg}^{-1}\right) \\
\text { K fixado médio }(\%)\end{array}$ & $\begin{array}{r}1232 \\
145 \\
76 \\
\end{array}$ & 200 \\
\hline 17 Vila Real & Cambissolo Dístrico de micaxistos & $\begin{array}{l}\text { K libertado }\left(\mathrm{mg} \mathrm{kg}^{-1}\right) \\
\text { K fixado }\left(\mathrm{mg} \mathrm{kg}^{-1}\right) \\
\text { K fixado médio }(\%)\end{array}$ & $\begin{array}{r}429 \\
40 \\
46\end{array}$ & 75 \\
\hline 11 Vale da Porca, Vimioso & Cambissolo Dístrico de filitos & $\begin{array}{l}\text { K libertado }\left(\mathrm{mg} \mathrm{kg}^{-1}\right) \\
\text { K fixado }\left(\mathrm{mg} \mathrm{kg}^{-1}\right) \\
\text { K fixado médio }(\%)\end{array}$ & $\begin{array}{r}579 \\
32 \\
39 \\
\end{array}$ & 75 \\
\hline 18 Alfândega da Fé & Cambissolo Dístrico de filitos & $\begin{array}{l}\mathrm{K} \text { libertado }\left(\mathrm{mg} \mathrm{kg}^{-1}\right) \\
\mathrm{K} \text { fixado }\left(\mathrm{mg} \mathrm{kg}^{-1}\right) \\
\text { K fixado médio }(\%)\end{array}$ & $\begin{array}{r}1215 \\
145 \\
70 \\
\end{array}$ & 200 \\
\hline 19 Curopos, Vinhais & Cambissolo Dístrico de filitos & $\begin{array}{l}\mathrm{K} \text { libertado }\left(\mathrm{mg} \mathrm{kg}^{-1}\right) \\
\mathrm{K} \text { fixado }\left(\mathrm{mg} \mathrm{kg}^{-1}\right) \\
\text { K fixado médio (\%) }\end{array}$ & $\begin{array}{r}647 \\
36 \\
41\end{array}$ & 75 \\
\hline 20 Mirandela & Leptossolo Dístrico de filitos & $\begin{array}{l}\mathrm{K} \text { libertado }\left(\mathrm{mg} \mathrm{kg}^{-1}\right) \\
\mathrm{K} \text { fixado }\left(\mathrm{mg} \mathrm{kg}^{-1}\right) \\
\text { K fixado médio }(\%)\end{array}$ & $\begin{array}{r}849 \\
5 \\
6 \\
\end{array}$ & 75 \\
\hline 12 Bragança & Luvissolo Crómico de peridotitos & $\begin{array}{l}\text { K libertado }\left(\mathrm{mg} \mathrm{kg}^{-1}\right) \\
\text { K fixado }\left(\mathrm{mg} \mathrm{kg}^{-1}\right) \\
\text { K fixado médio }(\%)\end{array}$ & $\begin{array}{r}239 \\
42 \\
38\end{array}$ & 100 \\
\hline 13 Izeda, Bragança & $\begin{array}{l}\text { Vertissolo Crómico de xistos anfibólicos e } \\
\text { depósitos argiláceos }\end{array}$ & $\begin{array}{l}\mathrm{K} \text { libertado }\left(\mathrm{mg} \mathrm{kg}^{-1}\right) \\
\mathrm{K} \text { fixado }\left(\mathrm{mg} \mathrm{kg}^{-1}\right) \\
\text { K fixado médio }(\%)\end{array}$ & $\begin{array}{r}39 \\
151 \\
54 \\
\end{array}$ & 350 \\
\hline 14 Frieira, Bragança & Leptossolo Crómico de xistos anfibólicos & $\begin{array}{l}\text { K libertado }\left(\mathrm{mg} \mathrm{kg}^{-1}\right) \\
\text { K fixado }\left(\mathrm{mg} \mathrm{kg}^{-1}\right) \\
\text { K fixado médio }(\%)\end{array}$ & $\begin{array}{r}47 \\
13 \\
5\end{array}$ & 200 \\
\hline 5 Roboredo, Torre de Moncorvo & Cambissolo Húmico de xistos e quartzitos & $\begin{array}{l}\text { K libertado }\left(\mathrm{mg} \mathrm{kg}^{-1}\right) \\
\text { K fixado }\left(\mathrm{mg} \mathrm{kg}^{-1}\right) \\
\text { K fixado médio }(\%)\end{array}$ & $\begin{array}{r}42 \\
25 \\
0\end{array}$ & 200 \\
\hline 16 Montalegre & Cambissolo Húmico Crómico de corneanas & $\begin{array}{l}\text { K libertado }\left(\mathrm{mg} \mathrm{kg}^{-1}\right) \\
\text { K fixado }\left(\mathrm{mg} \mathrm{kg}^{-1}\right) \\
\text { K fixado médio }(\%)\end{array}$ & $\begin{array}{l}25 \\
34 \\
26\end{array}$ & 100 \\
\hline 7 Sanhoane, Mogadouro & Alissolo Háplico de sedimentos grosseiros & $\begin{array}{l}\text { K libertado }\left(\mathrm{mg} \mathrm{kg}^{-1}\right) \\
\text { K fixado }\left(\mathrm{mg} \mathrm{kg}^{-1}\right) \\
\text { K fixado médio }(\%)\end{array}$ & $\begin{array}{l}53 \\
38 \\
51 \\
\end{array}$ & 100 \\
\hline
\end{tabular}


2. A capacidade de fixação do $\mathrm{K}$ variou entre $5 \mathrm{mg}$ de $\mathrm{K} \mathrm{kg}^{-1}$ para uma baixa taxa de aplicação $(25 \mathrm{mg}$ $\mathrm{K} \mathrm{kg}^{-1}$ de solo) e $157 \mathrm{mg}$ de $\mathrm{K} \mathrm{kg}^{-1}$ (quando se

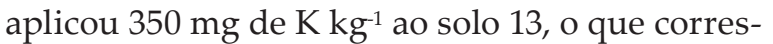
ponde à fixação de $314 \mathrm{~kg} \mathrm{~K} \mathrm{ha}^{-1}$ ). A percentagem média de fixação dos solos oscilou entre zero e $76 \%$ do K adicionado (no caso do solo 8);

3. A fixação do K aumentou com o K aplicado numa relação directa em todos os solos, com coeficientes de regressão que variaram entre 0,76 e 1 . Todavia, a percentagem do K fixado tinha propensão para baixar ou manter-se constante com a quantidade de $\mathrm{K}$ aplicada. Para o primeiro nível de aplicação de $\mathrm{K}$, a percentagem de $\mathrm{K}$ fixado atingiu $84 \%-85 \%$ nos solos 2 , 8 e 13, a qual foi depois baixando gradualmente. Quanto à capacidade de fixação do $K$ (expressa em percentagem), os solos foram agrupados do seguinte modo:

- Solos com capacidade de fixação nula ou baixa $(\leq 30 \%)-5,10,14,15,16,20$; - Solos com capacidade de fixação média $(31 \%-53 \%)-1,6,7,9,11,12,17,19$; - Solos com capacidade de fixação alta (> 53\%) $2,4,8,13,18$.

4. De entre os solos com capacidade de fixação alta, aquele que tinha o maior teor em argila (solo 13) estava exaurido de $\mathrm{K}$, enquanto os restantes quatro solos, além de fixarem muito $\mathrm{K}$, foram capazes de libertar elevada quantidade de $\mathrm{K}$ não permutável por cultivo intensivo. Este comportamento pode ser indicativo da reversibilidade do $\mathrm{K}$ fixado ou indicar que os solos possuem um elevado conteúdo em minerais ainda não alterados ou com baixo grau de meteorização. Esta situação poderá também ter ocorrido nos solos 11 e 19 (Quadro 2). Isto parece dever-se à elevada quantidade de ilite/mica nas três fracções do solo (argila, limo e areia fina) e, ainda, à grande capacidade que as gramíneas possuem de explorar estes minerais para a sua nutrição potássica.

5. Embora não sendo expectável que o solo 13 fixasse tanto K pela razão de os minerais argilosos dominantes serem esmectites, estas foram identificadas por Silva (1983) como beidelites, que, como se referiu anteriormente, devem a sua carga negativa às substituições isomórficas nas folhas tetraédricas e que, por isso, estabelecerão ligações "mais fortes" com o K+, que não é hidratável.
6. Os solos com capacidade de fixação alta têm, em média, $\mathrm{pH}$ mais elevado $\left(\mathrm{pH}_{\mathrm{H} 2 \mathrm{O}} 6,3\right)$, podendo conter carbonatos, como é o caso do solo 4 , enquanto os restantes grupos tinham em média $\mathrm{pH} \leq 5,5$.

7. Nos 12 solos com $\mathrm{pH}_{\mathrm{H} 2 \mathrm{O}} \leq 5,5$, quando submetidos a calagem, não ocorreu alteração assinalável na fixação do K, com excepção de dois solos (6 e 18), em que se observou um aumento da fixação do $\mathrm{K}$ de $51 \%$ para $66 \%$ e de $70 \%$ para $83 \%$, respectivamente (cf. Quadro 2). Na verdade, o que aconteceu com mais frequência foi o inverso, isto é, houve diminuição da fixação do $\mathrm{K}$ em metade dos solos $(1,7,16,17,19,20)$ e, no solo 20 , houve libertação do K. Ou seja, o K passou duma forma não permutável para uma forma acessível às plantas. Efectivamente, nos solos ácidos submetidos a calagem houve um aumento do $\mathrm{K}$ de troca e diminuição do $\mathrm{K}$ em solução e, consequentemente, aumentou o poder tampão desses solos, diminuindo, assim, a sua susceptibilidade à lixiviação do $\mathrm{K}$.

Desde há muito que os estudiosos repararam que, em condições de campo, os solos básicos, particularmente os solos com carbonatos, fixavam mais K do que os solos ácidos. Nos anos 30 do século passado, diversos investigadores testaram em laboratório o efeito do pré-tratamento das amostras de solo com soluções de diferentes valores de pH sobre a fixação do K nos solos. Estes estudos mostraram que aumentando o $\mathrm{pH}$ dessas soluções há a tendência para os solos fixarem mais $\mathrm{Ke}$, inversamente, provocando uma diminuição do $\mathrm{pH}$ dos solos, estes passaram a fixar menos K (Stanford, 1947; Sparks, 2001). Para valores de $\mathrm{pH}$ inferiores a 5-5,5, os catiões de $\mathrm{Al}$ (catiões aquo e hidroxo) dominam e podem ocupar os espaços intercamada dos minerais argilosos 2:1, mas, à medida que o $\mathrm{pH}$ sobe, $\mathrm{o}$ Al precipita, não podendo ocupar nem impedir o colapso dos espaços intercamada dos filossilicatos 2:1 pela entrada do K (Thomas e Hipp, 1968).

Em Portugal, em ensaios de adubação potássica com trigo no posto experimental de Castro Verde, houve sempre uma interacção negativa entre o K e o Ca aplicado na forma de cal apagada (Mourão, 1960). De facto, neste posto experimental, havia já indícios da fixação do K revelados pelos relatos de Alves (1984). Em oposição, Gama (1987) obteve um 
efeito inverso da calagem em 20 solos ácidos derivados de granitos $\left(\mathrm{pH}_{\mathrm{H} 2 \mathrm{O}} 4,3-5,4\right)$, a qual provocou, em geral, libertação do K. Na verdade, o efeito da aplicação de Ca tem sido matéria de controvérsia. $\mathrm{Na}$ prática, a sua aplicação através da calagem pode aumentar o $\mathrm{K}$ de troca, mas também pode aumentar o K fixado pelas razões acima apontadas. Com efeito, Gama (1987) constatou que, na grande maioria dos solos, houve libertação do $\mathrm{K}$ para a forma permutável, mas em três dos solos verificou-se que ocorreu fixação do K. Todavia, a libertação do K da forma não permutável só foi notória em dois solos (cerca de $60 \mathrm{mg} \mathrm{K} \mathrm{kg}^{-1}$ ), mas na maioria deles não ultrapassou $10 \mathrm{mg} \mathrm{K} \mathrm{kg}^{-1}$, e a fixação do $\mathrm{K}$ foi ainda mais irrelevante, não tendo ultrapassado $5 \mathrm{mg} \mathrm{K} \mathrm{kg}^{-1}$ de solo. Deste trabalho conclui-se que, nos solos ácidos derivados de granitos, a realização da calagem até valores de $\mathrm{pH}_{\mathrm{H} 2 \mathrm{O}} 5,2-6,4$, não induziu fixação do $K$, mas a tendência foi, sim, a de aumentar a sua libertação, embora em quantidades diminutas. Na maioria dos casos, a calagem dos solos ácidos tem mais um efeito benéfico em termos da nutrição potássica das plantas que o inverso, como também constataram Thomas e Hipp (1968) e Simonsson et al. (2007, 2009). Mesmo que a calagem induza alguma fixação do $K$, esta é temporária, pois um melhor desenvolvimento do sistema radicular das plantas irá promover maior libertação do K, devido ao maior contacto solo-raiz como, possivelmente, terá ocorrido nos solos 11, 18 e 19 submetidos a calagem (Portela, 1993). Portanto, estes solos libertaram uma quantidade assinalável de K não permutável (Quadro 2).

Mais recentemente, Portela et al. (2016) fizeram um estudo exploratório, que incidiu sobre nove solos localizados em diferentes regiões do país, mas com maior incidência no Alentejo, onde se suspeitava poder encontrar os solos mais fixadores de K. Os solos utilizados têm origem em diferentes materiais e o objectivo principal foi o de avaliar a capacidade de fixação do $\mathrm{K}$ em solos provenientes de diferentes litologias e com composição mineralógica diversa. A localização dos solos, o material originário e a classificação dos solos de acordo com WRB (2006) e a de Cardoso $(1965,1974)$ constam do Quadro 3. As características físico-químicas dos solos encontram-se no Quadro 4 e os procedimentos utilizados estão descritos em Portela et al. (2016).

Deste estudo, destacam-se os seguintes resultados:

1. A quantidade de $\mathrm{K}$ fixado variou entre $5 \mathrm{mg} \mathrm{kg}^{-1}$ de solo, para uma baixa taxa de aplicação de $\mathrm{K}$, e $582 \mathrm{mg} \mathrm{kg}^{-1}$. Este último valor corresponde à aplicação de $800 \mathrm{mg} \mathrm{K} \mathrm{kg}^{-1}$ a um solo com carbonatos (o que corresponde a uma fixação de $1164 \mathrm{~kg}$

Quadro 3 - Localização, material originário e classificação dos solos (adaptado de Portela et al., 2016)

\begin{tabular}{|c|c|c|c|c|}
\hline \multirow{2}{*}{ Solos } & \multirow{2}{*}{ Localização } & \multirow{2}{*}{ Material originário } & \multicolumn{2}{|c|}{ Classificação dos solos } \\
\hline & & & WRB (2006) & Cardoso $(1965,1974)$ \\
\hline $\begin{array}{l}\text { Limãos } \\
(\mathrm{LM})\end{array}$ & $\begin{array}{l}\text { Salselas } \\
\text { (Macedo de Cavaleiros) }\end{array}$ & Anfibolitos & $\begin{array}{l}\text { Cambissolo Vértico } \\
\text { (Êtrico) }\end{array}$ & $\begin{array}{l}\text { Litólico Não Húmico Pouco } \\
\text { Insaturado (Lb) }\end{array}$ \\
\hline $\begin{array}{l}\text { Soidos } 1 \\
\text { (SD1) }\end{array}$ & $\begin{array}{l}\text { Abitureiras } \\
\text { (Santarém) }\end{array}$ & Calcários e margas & $\begin{array}{l}\text { Calcissolo Hipocálcico } \\
\text { (Síltico) }\end{array}$ & $\begin{array}{l}\text { Calcário Pardo de Climas de Regime } \\
\text { Xérico Normal }\left(\mathrm{Pc}_{\mathrm{c}}\right.\end{array}$ \\
\hline $\begin{array}{l}\text { Soidos } 5 \\
\text { (SD5) }\end{array}$ & $\begin{array}{l}\text { Abitureiras } \\
\text { (Santarém) }\end{array}$ & Calcários e margas & $\begin{array}{l}\text { Calcissolo Hipocálcico } \\
\text { (Síltico) }\end{array}$ & $\begin{array}{l}\text { Calcário Pardo de Climas de Regime } \\
\text { Xérico Normal (Pcsd) }\end{array}$ \\
\hline $\begin{array}{l}\text { Rochão } \\
\text { (RC) }\end{array}$ & $\begin{array}{l}\text { Ladoeiro } \\
\text { (Idanha-a-Nova) }\end{array}$ & Arcoses & $\begin{array}{l}\text { Luvissolo Háplico } \\
\text { (Abrúptico) }\end{array}$ & $\begin{array}{l}\text { Mediterrâneo Pardo de Materiais Não } \\
\text { Calcários Normal (Pgn) }\end{array}$ \\
\hline $\begin{array}{l}\text { Degracias } \\
(\mathrm{DG})\end{array}$ & $\begin{array}{l}\text { Degracias } \\
\text { (Soure) }\end{array}$ & Calcários & $\begin{array}{l}\text { Luvissolo Háplico } \\
\text { (Crómico) }\end{array}$ & $\begin{array}{l}\text { Mediterrâneo Vermelho de Materiais } \\
\text { Calcários Normal (Vcd) }\end{array}$ \\
\hline $\begin{array}{l}\text { Azaruja } \\
(\mathrm{AZ})\end{array}$ & $\begin{array}{l}\text { St Justa } \\
\text { (Arraiolos) }\end{array}$ & Quartzodioritos & $\begin{array}{l}\text { Luvissolo Háplico } \\
\text { (Abrúptico, Endossódico) }\end{array}$ & $\begin{array}{l}\text { Mediterrâneo Pardo de Materiais Não } \\
\text { Calcários Normal (Pmg) }\end{array}$ \\
\hline $\begin{array}{l}\text { Lagoa } \\
(\mathrm{LG})\end{array}$ & $\begin{array}{l}\text { No Sra Machede } \\
\text { (Évora) }\end{array}$ & Gabrodioritos & $\begin{array}{l}\text { Luvissolo Háplico } \\
\text { (Abrúptico, Sódico) }\end{array}$ & $\begin{array}{l}\text { Mediterrâneo Pardo de Materiais Não } \\
\text { Calcários Normal (Pmg) }\end{array}$ \\
\hline $\begin{array}{l}\text { Viana do } \\
\text { Alentejo } \\
\text { (VA) }\end{array}$ & $\begin{array}{l}\text { Viana do Alentejo } \\
\text { (Viana do Alentejo) }\end{array}$ & Metagabros & $\begin{array}{l}\text { Luvissolo Háplico } \\
\text { (Sódico) }\end{array}$ & $\begin{array}{l}\text { Mediterrâneo Pardo de Materiais Não } \\
\text { Calcários Normal (Pmg) }\end{array}$ \\
\hline $\begin{array}{l}\text { Baleizão } \\
(\mathrm{BL})\end{array}$ & $\begin{array}{l}\text { Baleizão } \\
\text { (Beja) }\end{array}$ & Gabros & $\begin{array}{l}\text { Vertissolo Háplico } \\
\text { (Êtrico) }\end{array}$ & $\begin{array}{l}\text { Barro Castanho-Avermelhado Não } \\
\text { Calcário }(\mathrm{Cb})\end{array}$ \\
\hline
\end{tabular}


Quadro 4 - Características físico-químicas dos solos estudados em Portela et al. (2016)

\begin{tabular}{|c|c|c|c|c|c|c|c|c|c|}
\hline & LM & DG & RC & SD5 & SD1 & $\mathrm{AZ}$ & LG & VA & BL \\
\hline Profundidade do solo $(\mathrm{cm})$ & $0-25$ & $20-50$ & $20-50$ & $15-35$ & $15-35$ & $0-25$ & $0-25$ & $0-25$ & $0-25$ \\
\hline Argila $\left(\mathrm{g} \mathrm{kg}^{-1}\right)$ & 327 & 442 & 288 & 267 & 264 & 237 & 149 & 140 & 540 \\
\hline $\operatorname{Limo}\left(\mathrm{g} \mathrm{kg}^{-1}\right)$ & 138 & 312 & 61 & 482 & 480 & 95 & 106 & 30 & 210 \\
\hline Areia fina $\left(\mathrm{g} \mathrm{kg}^{-1}\right)$ & 378 & 220 & 144 & 99 & 100 & 531 & 409 & 548 & 202 \\
\hline Areia grossa $\left(\mathrm{g} \mathrm{kg}^{-1}\right)$ & 157 & 25 & 507 & 153 & 156 & 138 & 335 & 282 & 47 \\
\hline $\mathrm{pH}\left(\mathrm{H}_{2} \mathrm{O}\right)^{\mathrm{a}}$ & 6,5 & 7,1 & 5,3 & 7,8 & 8,1 & 5,7 & 7,2 & 7,0 & 7,0 \\
\hline Carbono orgânico $\left(\mathrm{g} \mathrm{kg}^{-1}\right)^{\mathrm{b}}$ & 6,1 & 6,0 & 1,5 & 13,8 & 8,4 & 5,8 & 4,5 & 3,7 & 6,3 \\
\hline K solução do solo $\left(\mathrm{mg} \mathrm{L}^{-1}\right)^{c}$ & 1,50 & 0,70 & 3,50 & 1,60 & 0,90 & 2,60 & 3,40 & 2,15 & 0,60 \\
\hline \multicolumn{10}{|l|}{ Catiões de troca $\left(\mathrm{cmol}_{\mathrm{c}} \mathrm{kg}^{-1}\right)^{\mathrm{d}}$} \\
\hline $\mathrm{Ca}$ & 8,61 & 17,52 & 8,05 & 35,28 & 26,40 & 10,40 & 9,92 & 8,32 & 31,52 \\
\hline $\mathrm{Mg}$ & 10,93 & 0,64 & 4,13 & 0,99 & 0,67 & 2,00 & 3,47 & 3,60 & 10,93 \\
\hline K & 0,16 & 0,40 & 0,18 & 0,29 & 0,14 & 0,08 & 0,11 & 0,08 & 0,10 \\
\hline $\mathrm{Na}$ & 0,17 & 0,49 & 0,21 & 0,17 & 0,07 & 0,13 & 0,43 & 0,65 & 0,44 \\
\hline $\mathrm{H}+\mathrm{Al}$ & 0,10 & 0,00 & 2,40 & 0,00 & 0,00 & 0,28 & 0,09 & 0,00 & 0,00 \\
\hline CTC efectiva ${ }^{\mathrm{e}}\left(\mathrm{cmol}_{\mathrm{c}} \mathrm{kg}^{-1}\right)$ & 19,96 & 19,04 & 14,98 & 36,72 & 27,27 & 12,89 & 14,01 & 12,64 & 42,99 \\
\hline $\mathrm{CaCO}_{3}\left(\mathrm{~g} \mathrm{~kg}^{-1}\right)^{\mathrm{f}}$ & - & - & - & 159 & 194 & - & - & - & - \\
\hline
\end{tabular}

a- razão solo/solução de 1:2,5; b- oxidação com $\mathrm{K}_{2} \mathrm{Cr}_{2} \mathrm{O}_{7}$; c- percolação (método de Adams, 1974); d- solução $1 \mathrm{M}$ de acetato de amónio pH 7 e o $\mathrm{H}+\mathrm{Al}$ pelo método $\mathrm{KCl}$ $1 \mathrm{M}$; e- capacidade de troca catiónica efectiva; f- por diferença entre o C total e o $\mathrm{C}$ orgânico.

$\mathrm{K} \mathrm{ha}^{-1}$ ). Os valores indicados referem-se, respetivamente, a um solo com baixa capacidade de fixação do $\mathrm{K}$ e a um solo com capacidade fixadora elevada, como é o caso do solo Soidos 5 (Abitueiras, Santarém).

2. Sete dos solos exibem capacidade de fixação do K relativamente elevada e nenhum deles mostrou indícios de que estivesse próximo da capacidade máxima de saturação do K. Por exemplo, para uma taxa de aplicação de $\mathrm{K}$ de $400 \mathrm{mg} \mathrm{kg}^{-1}$ (cerca de $800 \mathrm{~kg} \mathrm{~K} \mathrm{ha}^{-1}$ ), a capacidade de fixação deste elemento variou entre $40 \%$ e $86 \%$. De entre os solos mais ávidos de $\mathrm{K}$, encontram-se os solos ricos em carbonatos (Soidos 1 e Soidos 5), com uma capacidade de fixação entre $56 \%$ e $73 \%$ (taxa de aplicação de $\mathrm{K}$ de $800 \mathrm{mg} \mathrm{kg}^{-1}$ ), bem como os solos do Alentejo formados a partir de gabros, metagabros, gabrodioritos e quartzodioritos (BL, VA, LG e AZ, respectivamente). Nestes quatro solos, a capacidade de fixação do $\mathrm{K}$ variou entre $55 \%$ e 86\% (taxa de aplicação de K de $400 \mathrm{mg} \mathrm{kg}^{-1}$ ).

3. Os solos com maior capacidade para fixar $\mathrm{K}$ possuem, nas fracções argila e/ou limo, uma assinalável percentagem de vermiculites expansíveis (vermiculites de baixa carga), além de pequenas percentagens de vermiculite e/ou interestratificados mica-vermiculite. Em alguns destes solos, identificaram-se, ainda na fracção argila, minerais micáceos degradados, isto é, abertos, e que, por isso, exibem capacidade acrescida para fixar K. Na fracção areia fina destes solos, identificaram-se também vermiculites e micas, embora estes minerais ocorram em proporções mais modestas do que nas outras fracções mais finas;

4. Os solos que apresentam baixa capacidade de fixar $\mathrm{K}(\leq 30 \%)$ são os derivados de arcoses (RC, Castelo Branco) e de anfibolitos (LM, Bragança), nos quais não foi identificada vermiculite na fracção argila, mas sim elevada percentagem de esmectites, as quais mostram geralmente baixa capacidade para fixar o K (Borchardt, 1989);

5. Um dos solos derivados de calcários, mas que se mostra descarbonatado (DG), apresentou uma capacidade de fixação do $\mathrm{K}$ de $40 \%$ para taxas altas de aplicação de $\mathrm{K}(\geq 100 \mathrm{mg} \mathrm{kg}-1)$. Este solo contém, na fracção argila, elevada percentagem de minerais micáceos abertos;

6. Uma das principais conclusões deste estudo é que o material originário, particularmente em condições de clima mediterrânico (onde as condições de meteorização são, em regra, menos intensas), influencia a composição mineralógica 
das fracções argila, limo e areia fina dos solos, a qual é determinante para a capacidade de fixação do K pelo solo. Por conseguinte, a mineralogia de todas as fracções granulométricas mencionadas está, em muitos casos, na origem da ineficácia da adubação potássica, por levar o ião $\mathrm{K}^{+}$a ser redistribuído e fixado no solo em formas pouco acessíveis às plantas.

\section{IMPLICAÇõES AGRONÓMICAS DA FIXAÇÃO DO POTÁSSIO E RECOMENDAÇÃO DA ADUBAÇÃO POTÁSSICA}

A capacidade do solo para fornecer $\mathrm{K}$, a curto e a longo prazo, depende das características físico-químicas e mineralógicas dos solos. Estas características podem atribuir-se, em primeiro lugar, à composição do material originário, e, em segundo lugar, ao grau de desenvolvimento dos solos em função dos processos de meteorização ocorridos, mas também às práticas culturais, particularmente a adubação potássica. O cultivo intensivo do solo na ausência da aplicação de K é, em geral, o principal responsável pela sua exaustão, o que, em certos solos, pode levar à fixação do K. Em suma, o sistema cultural e o balanço entre as entradas e saídas (ganhos e perdas) do $\mathrm{K}$ podem determinar, em larga medida, a fixação deste nutriente.

Os estudos recentes que contemplam a mineralogia dos solos sugerem que a retenção e a libertação do $\mathrm{K}$ dos minerais 2:1 acompanham os balanços do K no solo (Barré et al., 2008; Simonsson et al., 2009). Assim, os filossilicatos do tipo 2:1 que ocorrem nas várias fracções do solo, que libertam e fixam $\mathrm{K}$, constituem, de facto, um reservatório deste elemento para as plantas. Com efeito, a fixação do K não é irreversível, podendo o K ser de novo libertado e utilizado por culturas subsequentes. Shaviv et al. (1985) e Goulding (1987) salientaram mesmo que a porção fixada do $\mathrm{K}$ pode tornar-se mais disponível para as plantas do que a fracção nativa do K. Portanto, o K fixado pode ser indicativo do potencial dum solo para libertar K. Alguns investigadores consideram que a fixação do K pelos solos não é tanto um processo que reduz a eficácia da adubação potássica, mas sim um factor favorável à limitação da lixiviação do K (Schneider et al., 2013).

\section{Os solos fixadores de potássio}

Nesta secção propõe-se uma lista dos solos fixadores de K, baseada nos dados actuais, sendo por isso provisória, e que teve em conta: a) resultados da experimentação de campo que visava a obtenção de respostas das culturas à adubação potássica, nos quais os autores demonstraram que o processo de retenção (fixação) do K ocorreu nos solos ensaiados; b) interpretações dos autores do trabalho experimental em vaso ou de campo, em que os indícios de se estar perante a fixação do $\mathrm{K}$ parecem ser a explicação mais plausível para as discrepâncias registadas nas respostas das culturas à adubação potássica; e, por fim, c) análise dos trabalhos laboratoriais nos quais foi demonstrada a fixação do K nos solos (não foram incluídos os solos que simultaneamente libertaram quantidade elevada de K, por serem solos pouco desenvolvidos). Na forma como foram agrupados os solos fixadores de $\mathrm{K}$ teve-se em conta a legenda da $\mathrm{FAO} /$ Unesco (1988) e WRB (2006) e entre parêntesis apresenta-se a respectiva correspondência na Carta de Solos de Portugal a Sul do Rio Tejo (Cardoso, 1965, 1974). Assim, os solos que até à data se revelaram fixadores de $\mathrm{K}$ foram:

\section{Regossolos}

Regossolos Calcáricos Eutricos (Pc- Calcários Pardos, de calcários não compactos)

\section{Fluvissolos}

Fluvissolos Calcáricos (Aac- Aluviossolos Modernos, de textura pesada com carbonatos)

\section{Cambissolos}

Cambissolos Calcáricos ( $\mathrm{Pc}^{\prime}-$ Calcários Pardos Para-Barros, de calcários não compactos associados a rochas cristalofílicas básicas)

\section{Calcissolos}

Calcissolos Háplicos (Vc- Calcários Vermelhos, de calcários)

Calcissolos Vérticos Crómicos (Vac'- Calcários, Vermelhos de Climas de Regime Xérico, ParaBarros, de rochas detríticas argiláceas calcárias)

\section{Luvissolos}

Luvissolos Háplicos Crómicos (Vcd-Mediterrâneos Vermelhos, de calcários compactos) 
Luvissolos Háplicos (Vx-Mediterrâneos Vermelhos ou Amarelos, de xistos)

Luvissolos Háplicos (Pm- Mediterrâneos Pardos

Para-Barros, de dioritos ou quartzodioritos)

Luvissolos Háplicos (Pmg- Mediterrâneos Pardos Normais, de quartzodioritos)

Luvissolos Órticos (Px- Mediterrâneos Pardos Normais, de materiais não calcários)

Luvissolos Gleizados ( $\mathrm{Pb}-$ Hidromórficos Sem Horizonte Eluvial, Para-Solos Hidromórficos Pouco Insaturados)

\section{Vertissolos}

Vertissolos Háplicos Êutricos (Bp- Barros Pretos Não Calcários, de dioritos ou gabros)

Vertissolos Êutricos (Bc- Barros Pardos Calcários Não Descarbonatados, de argilas calcárias)

Vertissolos Háplicos ( $\mathrm{Cb}-$ Barros CastanhoAvermelhados Não Calcários, de gabros)

Vertissolos Cálcicos Crómicos (Bvc- Barros Castanho-Avermelhados, de calcários)

Vertissolos Crómicos

\section{Estratégias da adubação potássica em solos fixadores de potássio}

A avaliação da disponibilidade do $\mathrm{K}$ no solo com vista à recomendação de adubos potássicos baseou-se, durante muitos anos, e até ao início de 1970, na determinação do K de troca pelo método de Mehlich $\left(\mathrm{Cl}_{2} \mathrm{Ba}-\mathrm{TEA}\right.$ ajustado a $\left.\mathrm{pH} 8,1\right)$, método este pouco adequado a este desiderato. Com efeito, de acordo com os trabalhos desenvolvidos pelas autoras e também o realizado por Fonseca et al. (2002), este método dá, com frequência, discrepâncias notórias com o método de Egnér-Riehm ou com o do acetato de amónio, em que o catião que permuta com o $\mathrm{K}^{+}$é o $\mathrm{NH}_{4}{ }^{+}$(utilizado quase universalmente), particularmente em solos fixadores de $\mathrm{K}$. Com efeito, o $\mathrm{Cl}_{2} \mathrm{Ba}-\mathrm{TEA}$ extrai cerca de metade do $\mathrm{K}$, como mostram os dados de Fonseca et al. (2002) ou mesmo um terço do K (dados de Portela et al., 2016), comparativamente à extracção com o ião amónio. Por conseguinte, é muito possível que se tenham submetido a ensaios de adubação potássica (entre 1930 e 1970) solos que a dispensavam. É, pois, provável que algumas das respostas inesperadas do trigo à adubação potássica, nesse período, se tenham devido ao uso deste método na avaliação da disponibilidade do K.
Quanto a outras particularidades das respostas do trigo aos adubos potássicos, há alguns aspectos que devem ser esclarecidos. Por um lado, os relatos de respostas economicamente compensadoras do trigo à adubação potássica e, por outro, o efeito depressivo do $\mathrm{K}$ registado em diversos ensaios de campo. Balbino (1961) revela que, embora as respostas ao $\mathrm{K}$ nas unidades-solo $\mathrm{Px}^{2}$ (Monforte), $\mathrm{Pv}^{2}$ (Elvas) e $\mathrm{Pmg}^{2}$ (Évora) não fossem estatisticamente significativas, eram economicamente compensadoras. De acordo com o autor, esse facto poderia atribuir-se às baixas taxas de aplicação de K na cultura do trigo. Ainda em 1979, Alves e colaboradores também reconheceram que as doses de $\mathrm{K}$ recomendadas para os ensaios de várias culturas de inverno e de primavera, aquando do III Plano de Fomento, entre 1968 e 1973, eram modestas (50-100 kg K $\mathrm{K}_{2} \mathrm{O} \mathrm{ha}{ }^{-1}$ ). Portanto, admite-se que, quando estivessem em causa solos fixadores de $\mathrm{K}$, as quantidades de adubo potássico a aplicar deveriam ter sido muito mais elevadas. Aliás, desde os anos 60 do século XX que Gama $(1966,1968)$ chamava a atenção para que se tivesse em consideração a fixação do K nos solos da região Sul do país aquando da recomendação da adubação potássica.

Quanto ao efeito depressivo do K sobre o trigo, Oliveira (1960), Balbino (1961) e Alves (1968) referem-se a alguns ensaios de campo em que as respostas ao $\mathrm{K}$ eram negativas, embora de valor absoluto reduzido. Alves avança com uma explicação para o efeito depressivo do $\mathrm{K}$, tendo admitido que «os elevados teores de sódio encontrados poderão não ser alheios à frequente ausência de resposta à adubação [potássica] » (Alves, 1968: pp. 92). Com efeito, o relatório de Alves et al. (1979) revela que determinadas unidades-solo (Pm, Pmg) onde foram instalados campos experimentais de aveia e trigo revelavam concentrações de $\mathrm{Na}$ de troca assinaláveis e muito superiores às do $\mathrm{K}$ de troca e, em $25 \%$ dos solos, era o $\mathrm{Mg}$ de troca que era superior ao Ca. No caso da aveia, as respostas negativas à adubação potássica foram também assinaladas por Alves et al. (1979) nas unidades-solo Pm. Ora, é bem conhecido o efeito desfloculante que o excesso de $\mathrm{Na}$ de troca provoca nos solos (associado, em alguns daqueles solos, a percentagens elevadas de areia fina), determinando condições físicas adversas; destruição da estrutura com a consequente diminuição drástica da dimensão dos poros e, por conseguinte, de escassez de 
oxigénio nas raízes. A elevada compacidade destas unidades-solo (Pm e Pmg) está bem patente no estudo de Fonseca et al. (2001), em que a densidade aparente é cerca de 1,7 nos vários horizontes do solo. A aplicação de um catião monovalente como o $\mathrm{K}$ poderia potenciar, temporariamente, ainda mais essas condições físicas desfavoráveis. $\mathrm{O}$ efeito desfloculante que a adição de $\mathrm{K}(\mathrm{como} \mathrm{KCl})$ pode exercer devido à sua aplicação ao solo foi registado aquando do trabalho laboratorial efectuado pelas autoras em dois conjuntos de amostras dos solos VA e LG (unidades-solo Pmg) (Portela et al., 2016). Estas condições físicas nefastas para as plantas também parecem ter ocorrido nos ensaios em vaso conduzidos por Almeida e Balbino (1960) aquando da calibração do método de Egnér-Riehm, referido anteriormente. Com efeito, e de um modo geral, todos os factores que limitem a expansão radicular restringem a absorção do $\mathrm{K}$ pelas plantas, particularmente a impedância mecânica (revelada pelos elevados valores da densidade aparente) e a ausência de arejamento de certos solos (Diest, 1978; Hallmark e Barber, 1981; Barber, 1984). Estes factores são mais relevantes em regiões com clima mediterrânico, onde os períodos de secura estival são, frequentemente, prolongados.

Face ao exposto e ao trabalho realizado em Portugal respeitante à fixação do $\mathrm{K}$ pelos solos, é fundamental, por um lado, ter em conta as características dos solos (e as suas limitações) e, por outro, as necessidades das plantas aquando da recomendação da adubação potássica.

Em primeiro lugar, há necessidade de agrupar os solos de acordo com as suas características físico-químicas e mineralógicas, na medida em que estas induzem determinados comportamentos-padrão. Nos solos fixadores de K, só é possível obter acréscimos de produção através de taxas de aplicação de K acima dos valores normais (ou seja, valores superiores a $150-200 \mathrm{~kg}$ de $\mathrm{K} \mathrm{ha}^{-1}$ ). Tendo em conta os agrupamentos dos solos fixadores de $\mathrm{K}$, não há dúvida de que, entre os solos mais fixadores, se encontram os solos com carbonatos, com capacidade de fixação superior a $50 \%$ e onde estão presentes minerais como mica/ilite e vermiculites. Estes solos são ávidos de $\mathrm{K}$ e, portanto, os investimentos em adubos potássicos poderão ser consideráveis, sob pena de a adubação ser ineficaz e o acréscimo de produtividade ficar adiado por vários anos, a menos que a adição de $\mathrm{K}$ ao solo seja acompanhada de aplicação foliar de K. Contudo, deve questionar-se se esta medida será, na maioria dos casos, economicamente viável.

Um outro grupo de solos fixadores são os que apresentam, na sua mineralogia, as vermiculites de baixa carga, como os Luvissolos Háplicos, Vertissolos Háplicos, Vertissolos Êutricos derivados de gabros, metagabros, gabrodioritos e quartzodioritos. É expectável que o K fixado seja algo reversível e, portanto, o investimento inicial não precise de ser muito elevado. Mas, note-se, que é preciso ter em conta que, dum modo geral, as camadas inferiores do solo são constituídas por minerais com uma capacidade de fixação do K superior à das camadas superficiais (Shaviv et al., 1985; Murashkina et al., 2007a,b), sendo os horizontes mais profundos verdadeiros sumidouros do K que se desloca ao longo do perfil. Marcelo et al. (2005) também verificaram que o $\mathrm{K}$ podia ser retido nas camadas mais profundas do perfil e estimaram em $780 \mathrm{~kg} \mathrm{~K} \mathrm{ha}^{-1}$ a quantidade de $\mathrm{K}$ retido (fixado) pelo solo até à profundidade de $50 \mathrm{~cm}$ ao fim de 10 anos de aplicação de $\mathrm{K}$ à taxa de $200 \mathrm{~kg} \mathrm{ha}^{-1}$ por ano.

Como mencionámos anteriormente, algum do K fixado é reversível, ou seja, pode ser libertado, como mostraram Simonsson et al. (2009). Porém, as taxas de libertação devem ser suficientemente elevadas para satisfazer as necessidades das plantas, o que nem sempre acontece, não dispensando, portanto, a adição K (Simonsson et al., 2007). Embora a recuperação do K fixado possa ocorrer, o espaço intercamada dos filossilicatos 2:1 deve estar razoavelmente preenchido com $\mathrm{K}$ até os solos serem capazes de libertar o nutriente a uma taxa adequada ao crescimento das culturas, nomeadamente daquelas com desenvolvimento rápido.

Em segundo lugar, a necessidade de adubação potássica é sobretudo função das exigências das plantas, as quais dependem do período de tempo em que absorvem o nutriente e das características do seu sistema radicular. Por exemplo, as gramíneas pratenses e os cereais de inverno são plantas com necessidades diárias de $\mathrm{K}$ reduzidas e, além disso, a elevada densidade do seu sistema radicular permite-lhes uma exploração eficiente do solo e, consequentemente, maior acesso ao K. Todavia, cultivares de curto prazo, como o milho e a batata, 
têm, pelo contrário, maiores necessidades diárias de K. Nas plantas fruteiras, como, por exemplo, a oliveira, que manifestam geralmente necessidades muito elevadas de K (Jordão, 1990), a hipótese da adubação foliar deve ser considerada sempre que se trate de solos ávidos de $\mathrm{K}$.

Em suma, em solos que se suspeitem ser fixadores de $\mathrm{K}$, nomeadamente os que foram agrupados na secção anterior, para a recomendação da adubação potássica deverá considerar-se a aplicação de taxas mais elevadas de K que compensem o K fixado pelo solo. No caso de solos com carbonatos, que exigem aplicações maciças de K, deverá ser estudada a sua aplicação por via foliar, nomeadamente no olival. Relativamente ao trigo, a questão da necessidade de aplicação de taxas elevadas de adubo potássico foi, há muito, ponderada por Alves (1984), quando referiu que a opção por uma elevação gradual da disponibilidade de $\mathrm{K}$ ou pela aplicação maciça de K que promova, a curto prazo, a subida do K disponível no solo será uma opção de ordem económica e caberá ao agricultor fazê-la.

Segundo Jordão e Marcelo (1991), a aplicação de K por via foliar no olival terá sido experimentada em 1986, embora não se viessem a conhecer os seus resultados. Todavia, o seu efeito positivo é reconhecido por Sbitri e Serafini (2007). Este método de aplicação do K na forma de sais (cloreto, sulfato, nitrato) tem sido encorajado sempre que a análise foliar revele desequilíbrios nutritivos (DGADR, 2010), ou «nos casos em que se verifique uma insuficiente absorção de nutrientes através do sistema radicular devido a condições deficientes de solo e clima», nomeadamente no olival (Jordão, 2014; Jordão e Marcelo, 2005).

Apesar de, em Portugal, as respostas das culturas ao $\mathrm{K}$ terem sido consideradas como raras ou nulas, a preocupação de não se exaurir o solo está bem patente em várias recomendações de agrónomos. Com efeito, cautelosamente sugeriram que a adubação potássica não deveria ser descurada e deveria compensar a saída do nutriente através das culturas (Balbino et al., 1966; Santos, 1973, 1974; Alves et al., 1979). Santos (1974) recomendava mesmo a utilização de adubos compostos NPK com o objectivo de encorajar os agricultores a aplicar o K com vista a «uma adubação completa e equilibrada».

\section{NOTAS}

1. O termo potássio 'assimilável' é utilizado neste artigo tal como empregado por Almeida e Balbino (1960) para designar o K extraído por uma solução de lactato de amónio e ácido acético tamponizada a $\mathrm{pH}$ 3,7. Todavia, foi substituído ao longo do texto por K extraível.

2. Correspondência da classificação das unidades-solo na classificação portuguesa (Cardoso, 1965, 1974) e FAO/Unesco (1988) ou WRB (2006) referidas no texto:

Px- Mediterrâneos Pardos Normais, de materiais não calcários (Luvissolos Órticos; $\mathrm{FAO} /$ Unesco, 1988);

$\mathrm{Pb}$ - Hidromórficos Sem Horizonte Eluvial, Para-Solos Argiluviados Pouco Insaturados (Luvissolos Gleizados; FAO/Unesco, 1988);

Aac- Aluviossolos Modernos de textura pesada comcarbonatos(FluvissolosCalcários,WRB2006); Vc- Calcários Vermelhos, de calcários (Calcissolos Háplicos, WRB, 2006);

Pc'-Calcários Pardos Para-Barros, de calcários não compactos associados a rochas cristalofílicas básicas (Cambissolos Calcáricos, WRB, 2006);

Bp- Barros Pretos, Não Calcários, de dioritos, gabros ou outras rochas eruptivas básicas, ou cristalofílicas básicas (Vertissolos Háplicos Êtricos, WRB, 2006);

Vac- Calcários Vermelhos Normais, de rochas detríticas argiláceas calcárias (Calcissolos Lúvicos Crómicos, WRB, 2006);

Pc-Calcários Pardos Normais, de calcários não compactos (Regossolos Calcáricos Êutricos, WRB, 2006);

Pm- Mediterrâneos Pardos, de dioritos (Luvissolos Háplicos, WRB, 2006);

Pmg- Mediterrâneos Pardos, de quartzo-dioritos (Luvissolos Háplicos, WRB, 2006);

$\mathrm{Pv}$ - Mediterrâneos Vermelhos e Amarelos de Materiais Não Calcários, de rochas cristalofílicas básicas (Luvissolos crómicos, WRB, 2006); Vx- Mediterrâneos Vermelhos ou Amarelos, de xistos (Luvissolos Háplicos, WRB, 2006); Bc- Barro Pardo Calcário Não Descarbonatado, de argilas (Vertissolos Êutricos, WRB, 2006); Cpc-Barros Pretos Calcários Não Descarbonato, de margas (Vertissolos, WRB, 2006). 
3. Pcx- Calcários Pardos, de xistos associados a depósitos calcários (Calcissolos, WRB, 2006); Pmg- Mediterrâneos Pardo, de quartzo-dioritos (Luvissolos Háplicos) com argila - 6,7\% e K troca - 0,16 $\mathrm{cmol}_{\mathrm{c}} \mathrm{kg}^{-1} ; \mathrm{Pm}$ - Mediterrâneos Pardos, de dioritos (Luvissolos Háplicos) com argila $15,9 \%$ e $\mathrm{K}$ troca $-0,20 \mathrm{cmol}_{\mathrm{c}} \mathrm{kg}^{-1}$; Vc- Calcários Vermelhos, de calcários (Calcissolos Háplicos) com argila $-25,7 \%$ e K troca - 1,52 $\mathrm{cmol}_{\mathrm{c}} \mathrm{kg}^{-1}$; Bvc- Barro Castanho-Avermelhado, de calcários (Vertissolos Cálcicos) com argila - 53,4 \% e $\mathrm{K}$ troca $-0,85 \mathrm{cmol}_{\mathrm{c}} \mathrm{kg}^{-1}$.

4. Pg- Litólicos não Húmicos, de granitos (Cambissolos Háplicos) com argila - 9,0 \% e $\mathrm{K}$ troca $-0,64 \mathrm{cmol}_{\mathrm{c}} \mathrm{kg}^{-1}$; Bpc- Barros Pretos Calcários Muito Descarbonatados, de dioritos ou gabros (Vertissolos Cálcicos) com argila - 51,1 \% e K troca - 0,41 $\mathrm{cmol}_{\mathrm{c}} \mathrm{kg}^{-1}$; Px (fd)-Mediterrâneos Pardos, de xistos, fase delgada (Luvissolos Órticos) com argila - 21,5 \% e K troca - 0,20 $\mathrm{cmol}_{c} \mathrm{~kg}^{-1} ; \mathrm{Vx}-$ Mediterrâneos Vermelhos ou Amarelos, de xistos (Luvissolos Háplicos) com argila $-11,8 \%$ e K troca $-0,25 \mathrm{cmol}_{\mathrm{c}} \mathrm{kg}^{-1}$.

\section{AGRADECIMENTOS}

Os nossos agradecimentos vão para os colegas Pedro Jordão, Encarnação Marcelo, Raquel Mano e Corina Carranca do INIAV, pela disponibilização de relatórios internos das respectivas instituições, pelo empenho na recolha bibliográfica e no fornecimento de informação relevante para este trabalho. Agradecemos também aos colegas Afonso Martins da UTAD, Fernando Girão Monteiro e Nuno Cortez do ISA pela ajuda prestada na classificação dos solos. As análises químicas apresentadas no Quadro 3 foram efectuadas no Laboratório de Solos e Plantas da UTAD e tiveram o apoio financeiro do CITAB. José Carlos Rego colaborou nas tarefas de campo e de preparação das amostras de solos. Este trabalho teve, também, o apoio financeiro da Unidade de Investigação LEAF (FCT Ref. UID/AGR/04129/2013).

\section{REFERÊNCIAS BIBLIOGRÁFICAS}

Adams, F. (1974) - Soil solution. In: Carson, E.W. (Ed.) - The plant root and its environment. University Press of Virginia, Charlottesville, p. 441-481.

Agroconsultores-Coba (1991) - Carta de Solos, Carta do Uso Actual da Terra e Carta de Aptidão da Terra do Nordeste de Portugal, Escala 1:100000. Peças Desenhadas e Memórias Descritivas. Universidade de Trás-os-Montes e Alto Douro, Vila Real.

Almeida, L.A.V. (1958) - L'útilisation des engrais potassiques au Portugal. Kalium Symposium 1958, International Potash Institute, Berna, p. 65-71.

Almeida, L.A.V. e Balbino, L.R. (1960) - Determinação do fósforo e do potássio assimiláveis em alguns solos do País. Anais do Instituto Superior de Agronomia, vol. 23, p. 19-42.

Alves, J.A. (1965-1967) - Projecto de fertilização mineral e correcção do solo. I. Fertilização mineral. Plano Intercalar de Fomento (1965-1967). Direcção Geral dos Serviços Agrícolas, Lisboa.

Alves, J.A. (1968) - Fertilização do trigo. Revista Agronómica, vol. 51, tomos I-II, p. 85-94.

Alves, J.A. (1984) - Adubação potássica e a calagem nos Solos Mediterrâneos Pardos de materiais não calcários no 'Campo Branco' - Castro Verde. Relatório apresentado ao INIAER do Instituto Nacional de Investigação Agrária. 21p. [dactilografado]

Alves, J.A. e Cardoso, J.C. (1967) - Empreendimento de fertilização mineral e correcção do solo - II Plano de fomento. I - Fertilização mineral. Direcção Geral dos Serviços Agrícolas, Lisboa. [dactilografado]

Alves, J.A. e Silva, J.F. (1958) - Azoto, fósforo, e potássio extraídos do solo pelo trigo. Melhoramento, vol. 11, separata, p. 5-31.

Alves, J.A.; Nogueira, M.G.B.; Santos, A.D. e Tavares, M.M.S. (1979) - Fertilização mineral e correcção do solo. I Fertilização mineral. Investigação não ligada ao Ensino - Projecto 4. Direcção Geral dos Serviços Agrícolas. Laboratório Rebelo da Silva. III Plano de Fomento (1968-1973). Direcção Geral de Extensão Rural. Lisboa, 412p. [dactilografado] 
Balbino, L.R. (1961) - Reacção do trigo ao azoto, fósforo e potássio (5 anos de experimentação). Departamento de Solos e Fertilizantes do Centro de Investigação da CUF, Lisboa. 35p.

Balbino, L.R. (1963a) - Correlation between the results of soil analysis $\left(\mathrm{P}_{2} \mathrm{O}_{5}\right.$ and $\left.\mathrm{K}_{2} \mathrm{O}\right)$ and those of pot and field experiments. International Superphosphate Manufactorers' Association, Agricultural Committee, Paris. 28 p.

Balbino, L.R. (1963b) - Determinação do fósforo e do potássio 'assimiláveis' em alguns solos do país. Calibração dos métodos de Truog-Hellige e Egnér-Riehm por meio de ensaios em vaso e de campo. Agronomia Lusitana, vol. 25, n. 3, p. 231-246.

Balbino, L.R. (1968) - O método de Egnér-Riehm na determinação do fósforo e potássio 'assimiláveis' em solos de Portugal. Revista Agronómica, vol. 51, tomos I-II, p. 47-58.

Balbino, L.R.; Brito, F.V. e Carvalho-Pereira, A.J. (1966) - Adubação do trigo no Alentejo. II - Barros Pretos e Vermelhos. Ao Serviço da Lavoura, vol. 64, p. 3-10.

Balbino, L.R.; Carvalho-Pereira, A.J. e Vieira de Brito, F.V. (1963) - Reacção do trigo ao azoto, fósforo e potássio. Agronomia Lusitana, vol. 25 n. 5, p. 661-673.

Barber, S.A. (1984) - Soil nutrient bioavailability: A mechanistic approach. John Wiley, New York, 398 p.

Barré, P.; Velde, B.; Fontaine, C.; Catel, N. e Abbadie, L. (2008) - Which 2:1 clay minerals are involved in the soil potassium reservoir? Insights from potassium addition or removal experiments on three temperate grassland soil clay assemblages. Geoderma, vol. 146, n. 1-2, p. 216-223. http://dx.doi.org/10.1016/j.geoderma.2008.05.022

Borchardt, G., (1989) - Smectites. In: Dixon J.B. e Weed S.B. (Eds.) - Minerals in soil environments (2.. ed.). Soil Science Society of America, Madison, p. 675-727.

Brito, F.V. (1968) - Contribuição para o estudo dos problemas da fertilização da oliveira. Revista Agronómica, vol. 51, tomo I-II, p. 3-13.

Cardoso, J.C. (1965) - Os solos de Portugal. Sua classificação, caracterização e génese. 1 - A Sul do rio Tejo. Direcção Geral dos Serviços de Agricultura, Lisboa. 311 p.

Cardoso, J.C. (1974) - A classificação dos solos de Portugal: Nova Versão. Boletim de Solos do SROA, vol. 17, p. 14-46.

Carranca, C.F.; Baeta, J. e Fragoso, M.A.C. (1993) - Effect of NK fertilization on leaf nutrient content and fruit quality of 'Valencia late' orange trees. In: Fragoso, M.A.C. e Beusichem, M.L. (Eds.) - Optimization of plant nutrition. Kluwer Academic Publishers, Dordrecht, p. 445-448.

Cook, M.G. e Hutcheson, T.B. (1960) - Soil potassium reactions as related to clay mineralogy of selected Kentucky soils. Soil Science Society of America Journal, vol. 24, n. 4, p. 252-256. http://dx.doi.org/10.2136/ sssaj1960.03615995002400040012x

DGADR (2010) - Produção integrada do olival (2. ․ ed.), Ministério da Agricultura, do Desenvolvimento Rural e das Pescas, Lisboa. http://www.drapc.min-agricultura.pt/base/documentos/prodi_olival_2ed.pdf

Dias, J.C.S.; Santos, A.D.; Nogueira, M.G.B. e Tavares, M.M.R.S. (1980) - Guia prático da fertilização (2.ㄹ ed.). Serviço de análises de terra e de análise foliar. Laboratório Químico-Agrícola Rebelo da Silva, Ministério de Agricultura e Pescas e Direcção Geral de Extensão Rural, Lisboa. 72 p.

Diest, A. van (1978) - Factors affecting the availability of potassium in soils. In: Potassium Research Review and Trends. Proc. 11th Congress of International Potash Institute, Berne, p. 75-97.

Dowdy, R.H. e Hutcheson, T.B. (1963) - Effect of exchangeable potassium level and drying on release and fixation of potassium by soils as related to clay mineralogy. Soil Science Society of America Journal, vol. 27, n. 1, p. 31-34. http://dx.doi.org/10.2136/sssaj1963.03615995002700010014x

Fanning, D.V.; Keramidas, V.Z. e El-Desoky, M.A. (1989) - Micas. In: Dixon J.B. e Weed S.B. (Eds.) - Minerals in soil environments (2. ${ }^{a}$ ed.). Soil Science Society of America, Madison, p. 551-674.

FAO/Unesco (1988) - Soils map of the world: Revised legend. World Soil Resources Report 60, Rome. 89 p.

Fernandes, M.O. (1899) - A cultura do trigo pelos adubos chimicos no Baixo Alentejo. Boletim da Real Associação Central da Agricultura Portugueza, vol. 1, p. 162-199.

Fonseca, M.; Furtado, A.F.A.; Monteiro, F. e Madeira, M. (2001) - A mineralogia da fracção argilosa de solos Mediterrâneos Pardos de Materiais Não Calcários da região do Alentejo. Revista de Ciências Agrárias, vol. 24, n. 3-4, p. 22-30.

Fonseca, M.; Monteiro, F.; Madeira, M. e Furtado, A.F.A. (2002) - A mineralogia e o complexo de troca de solos argiluviados da região de Évora-Beja. Revista de Ciências Agrárias, vol. 25, n. 3-4, p. 42-52. 
Gama, M.V. (1961) - Sobre o método de Volk para avaliação da capacidade de fixação de potássio dos solos. Agronomia Lusitana, vol. 23, p. 117-128.

Gama, M.V. (1963) - Fixação de potássio em relação com as quantidades aplicadas nalguns solos. Agronomia Lusitana, vol. 25, p. 701-707.

Gama, M.V. (1966) - Influência da secagem ao ar na libertação e na fixação de potássio em oito solos. Agronomia Lusitana, vol. 27, p. 145-165.

Gama, M.V. (1968) - Algumas considerações sobre as disponibilidades de potássio nos solos. Revista Agronómica, vol. 51, tomos I-II, p. 57-63.

Gama, M.V. (1981) - Adubação potássica na cultura do trigo. Pedologia, vol. 16, n. 2, p. 173-176.

Gama, M.V. (1987) - Efeito do carbonato de cálcio na mobilização do potássio e do magnésio numa série de vinte amostras de solos ácidos derivados de granitos. Agronomia Lusitana, vol. 42, n. 3-4, p. 285-300.

Gama, M.V. (1988) - Evolução dos teores de potássio, fósforo e azoto num solo dum ensaio de adubação de laranjeiras. Pedologia, vol. 23 n. 2, p. 83-88.

Goulding, K.W.T. (1987) - Potassium fixation and release. In: Methodology in soil-K research. Proc. 20 $0^{\text {th }}$ Colloquium of International Potash Institute, Baden. Vienna, p. 125-142.

Graça, L.Q. (1939) - Os adubos em Portugal. Direcção Geral dos Serviços Agrícolas do Ministério da Agricultura, Lisboa. 44 p.

Hallmark, W.B. e Barber, S.A. (1981) - Root growth and morphology, nutrient uptake, and nutrient status of soybeans as affected by soil $\mathrm{K}$ and bulk density. Agronomy Journal, vol. 73, n. 5, p. 779-782. https://doi. org/10.2134/agronj1981.00021962007300050008x

Jordão, P.V. (1989) - Nutrição e fertilização da oliveira. Instituto Nacional de Investigação Agrária, LQARS, Lisboa. 82 p.

Jordão, P.V. (1990) - Efeito da aplicação de fertilizantes na composição mineral de folhas de oliveira. Tese de mestrado. Instituto Superior de Agronomia, Universidade Técnica de Lisboa. 99 p.

Jordão, P.V. (coord.) (2014) - Boas práticas no olival e no lagar. Instituto de Investigação Agrária e Veterinária, Camarate. 290 p.

Jordão, P.V. e Marcelo, M.E. (1991) - Algumas considerações sobre os estudos realizados em Portugal no âmbito da fertilização da oliveira. Comunicação apresentada ao IX Encontro Nacional de Técnicos de Olivicultura, Gafanha da Nazaré. 19 p.

Jordão, P.V. e Marcelo, M.E. (2005) - Olival, fertilização racional. Cadernos Rurais nº 6, INIAP, Laboratório Químico-Agrícola Rebelo da Silva, Associação para a Valorização Agrícola em Protecção Integrada, Alcobaça. 39 p.

Jordão, P.V.; Marcelo, M.E.; Centeno, M.S.; Matias, H.; Rogado, B.; Pinheiro-Alves, M.C. e Calouro, F. (2003) - Influência da fertilização com fósforo e potássio na produção da oliveira e na qualidade do azeite da cultivar Blanqueta em solos derivados de calcário. In: III Simpósio Nacional de Olivicultura, Castelo Branco, 29-31 de Outubro 2003, p. 69-76

Kuhlmann, H. (1990) - Importance of the subsoil for K nutrition of crops. Plant and Soil, vol. 127, n. 1, p. 129-136.

LQARS (2000) - Manual de fertilização de culturas. Laboratório Químico Agrícola Rebelo da Silva, INIA. Lisboa. 221 p.

Marcelo M.E.; Jordão, P.V.; Simões, A.M.; Santos, L.M.S.; Cordeiro, A.M.; Costa, A.S.V. e Soveral-Dias, J.C. (2005) - Influência de aplicação de azoto e potássio a um olival instalado em solos calcários sobre os teores de potássio do solo. Revista de Ciências Agrárias, vol. 28, n. 2, p. 189-197.

Marcelo, M.E. (2001). Influência da adubação azotada, potássica e magnesiana em aspectos quantitativos e qualitativos da produção da oliveira. Tese de doutoramento. Instituto Superior de Agronomia, Universidade Técnica de Lisboa. 184 p.

Marcelo, M.E.; Boteta, L.; Piçarra I.; Infante, J.; Varela, M.; Figueira, M.; Santos, F.; Santos, L.; Miranda, A. e Jordão, P.V. (2011) - Efeito da fertirrega com azoto e potássio num olival nos teores de nitratos e de potássio do solo. Revista de Ciências Agrárias, vol. 34, n. 2, p. 173-180.

Mengel, K. (1985) - Dynamics and availability of major nutrients in soils. Advances in Soil Science, vol. 2, p. 65-131. https://doi.org/10.1007/978-1-4612-5088-3_2 
Mourão, H.F.C. (1960) - Análise estatística dos ensaios de adubação efectuados nos postos experimentais de sequeiro. 5. Castro Verde. Agronomia Lusitana, vol. 22, p. 321-338.

Murashkina, M.A.; Southard, R.J. e Pettygrove, G.S. (2007a) - Potassium fixation in San Joaquin Valley soils derived from granitic and nongranitic alluvium. Soil Science Society of America Journal, vol. 71, n. 1, p. 125-132. http://dx.doi.org/10.2136/sssaj2006.0060

Murashkina, M.A.; Southard, R.J. e Pettygrove, G.S. (2007b) - Silt and fine sand fractions dominate potassium fixation in soils derived from granitic alluvium of the San Joaquin Valley, California. Geoderma, vol. 141, n. 3-4, p. 283-293. https://doi.org/10.1016/j.geoderma.2007.06.011

Najafi-Ghiri, M. e Abtahi, A. (2013) - Potassium fixation in soil size fractions of arid soils. Soil and Water Research, vol. 8, n. 2, p. 49-55.

Oliveira, A.J. (1960) - Fertilização mineral em agricultura. Apuramento estatístico dos ensaios de adubação efectuados em Portugal desde a campanha do trigo. Revista de Economia, vol. 13, n. 1, p. 17-40.

Portela, E.A.C. (1989) - Avaliação da disponibilidade de potássio em solos de Trás-os-Montes. Contributo para o seu estudo. Tese de doutoramento. Universidade de Trás-os-Montes e Alto Douro, Vila Real. 219 p.

Portela, E.A.C. (1993) - Potassium supplying capacity of northeastern Portuguese soils. Plant and Soil, vol. 154, n. 1, p. 13-20. https://doi.org/10.1007/BF00011065

Portela, E.; Monteiro, F.; Fonseca, M. e Abreu, M.M. (2016) - Fixação do potássio em solos com diferente mineralogia. In: Actas do VII Congresso Ibérico das Ciências do Solo, 13-15 de Setembro de 2016, Instituto Politécnico de Beja, p 169-172

Rich, C.I. (1968) - Mineralogy of soil potassium. In: Kilmer V.J.; Younts, S.E. e Prady, N.C. (Eds.) - The role of potassium in agriculture. Soil Science Society of America, Madison, p.79-108.

Santos, J.Q. (1973) - Aspectos gerais da fertilização. In: Palestras sobre fertilização. Amoníaco Português, Lisboa, p. 63-72.

Santos, J.Q. (1974) - Aspectos gerais da fertilização. Amoníaco Português, Lisboa. 142p.

Sbitri, M.O. e Serafini, F. (Coord.). (2007) - Production tecniques in olive growing. International Olive Council, Spain. www.internationaloliveoil.org/store/download/40

Schneider, A.; Tesileanu, R.; Charles, R. e Sinaj, S. (2013) - Kinetics of soil potassium sorption-desorption and fixation. Communications in Soil Science and Plant Analysis, vol. 44, n. 1-4, p. 837-849. https://doi.org/10.10 80/00103624.2013.749442

Seabra A.L. (1935) - A Oliveira. Preceitos para a sua cultura racional (2. ․ ed.). Companhia União Fabril e Imperial Chemical Industries, LTD, Lisboa. 73 p.

Shaviv, A.; Mohsin, M.; Pratt, P.F. e Mattigod, S.V. (1985) - Potassium fixation characteristics of five southern California soils. Soil Science Society of America Journal, vol. 49, n. 5, p. 1105-1110.

Silva, J.M.V. (1983) - Estudo mineralógico da argila e do limo de solos derivados de granitos e rochas básicas da região de Trás-os-Montes. Garcia de Orta (série Estudos Agronómicos), vol. 10, n. 1-2, p. 27-36.

Simonsson, M.; Andersson, S.; Andrist-Rangel, Y.; Hillier, S.; Mattsson, L. e Öborn, I. (2007) - Potassium release and fixation as a function of fertilizer application rate and soil parent material. Geoderma, vol. 140, n. 1-2, p. 188-198. https://doi.org/10.1016/j.geoderma.2007.04.002

Simonsson, M.; Hillier, S. e Oborn, I. (2009) - Changes in clay minerals and potassium fixation capacity as a result of release and fixation of potassium in long term field experiments. Geoderma, vol. 151, n. 3-4, p. 109-120. https://doi.org/10.1016/j.geoderma.2009.03.018

Sparks, D.L. (2001) - Dynamics of K in soils and their role in management of K nutrition. In: K in nutrient management for sustainable crop production in India. IPI-PRII. New Deli, India, p.79-101.

Stanford, G. (1947) - Fixation of potassium in soils under moist conditions and on drying in relation to type of clay mineral. Soil Science Society of America. Proceedings, vol. 12, p. 167-171.

Thomas, G.W. e Hipp, B.W. (1968) - Soil factors affecting potassium availability. In: Kilmer V.J.; Younts, S.E. e Prady, N.C. (Eds.) - The role of potassium in agriculture. Soil Science Society of America, Madison, p. 269-291.

WRB (2006) - World reference base for soil resources. A framework for international classification, correlation and communication. Food and Agriculture Organization of the United Nations, Rome. 128 p. 